MÁRIO LEITE PEREIRA FILHO

\title{
APLICAÇÃO DO MÉTODO DE IMAGENS COMPLEXAS AO CÁlCULO DE MALHAS DE ATERRAMENTO EM SOLOS COM ESTRATIFICAÇÃO HORIZONTAL
}

Dissertação apresentada à Escola Politécnica da USP para obtenção do título de Mestre em Engenharia Elétrica.

São Paulo

1999 
MÁRIO LEITE PEREIRA FILHO

\section{APLICAÇÃO DO MÉTODO DE IMAGENS COMPLEXAS AO CÁlCULO DE MALHAS DE ATERRAMENTO EM SOLOS COM ESTRATIFICAÇÃO HORIZONTAL}

Dissertação apresentada à Escola Politécnica da USP para obtenção do título de Mestre em Engenharia Elétrica.

Área de Concentração:

Sistemas de Potência

Orientador:

Prof. Dr. José Roberto Cardoso

São Paulo

1999 
1. INTRODUÇÃO

2. ESTADO DA ARTE NO CÁLCULO DE MALHAS DE ATERRAMENTO.............4

3. FORMULAÇÃO GERAL DO MÉTODO DAS IMAGENS COMPLEXAS PARA

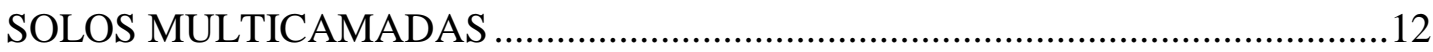

3.1 Formulação das equações íntegro-diferenciais ...................................................13

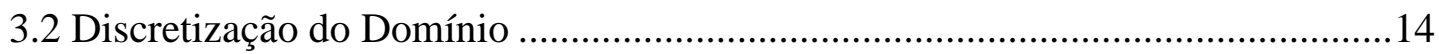

3.3 Resistências mútuas de eletrodos lineares .........................................................16

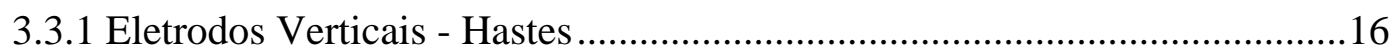

3.3.2 Eletrodos Inclinados ou horizontais - Cabos.............................................19

3.4 Introdução de Eletrodos Passivos .................................................................21

4. DETERMINAÇÃO DAS FUNÇÕES DE GREEN ...............................................23

4.1 Fonte pontual em meio homogêneo.................................................................23

4.2 Fonte pontual em meio estratificado horizontalmente, fonte e objeto na mesma

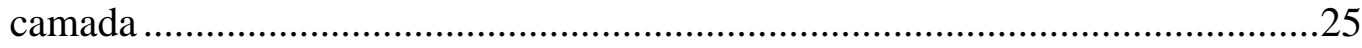

4.2.1 Coeficientes de Reflexão e Transmissão .....................................................22

4.2.2 Solução para a função kernel ...............................................................28

4.3 Fonte pontual em meio estratificado horizontalmente, fonte e objeto em camadas

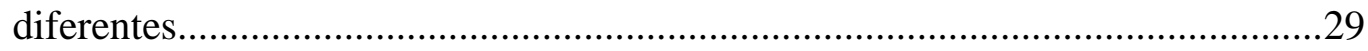

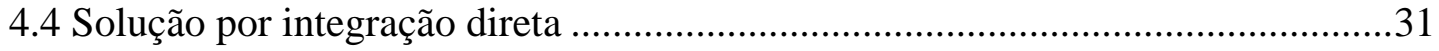

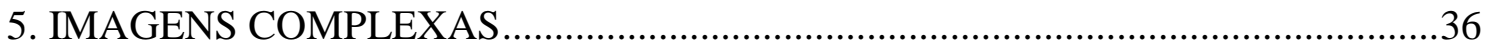

5.1 Imagens Complexas tal como apresentadas por Chow et all [29] ........................36 


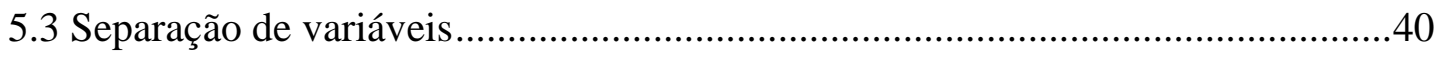

5.3.1 Fonte e objeto na mesma camada. ..........................................................41

5.3.2 Fonte e o objeto em camadas diferentes. ...................................................43

5.4 Determinação dos Pólos e Resíduos das Imagens ..............................................45

5.4.1 Método de Prony como apresentado por Chow et all ...................................46

5.4.2 Método de Prony com solução por autovalores ….....................................48

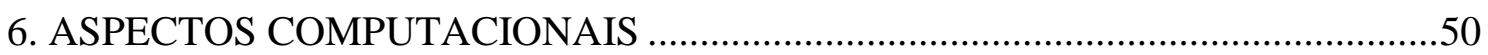

6.1 Entrada de Dados da Malha e do Solo................................................................50

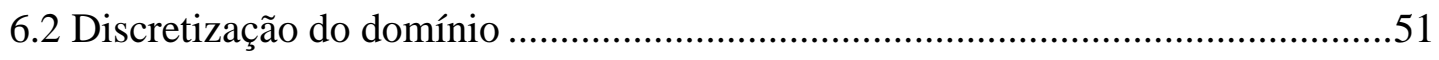

6.3 Determinação das imagens complexas ..........................................................

6.4 Montagem da matriz de resistências mútuas ......................................................52

6.5 Cálculo dos potenciais e exploração dos resultados ............................................53

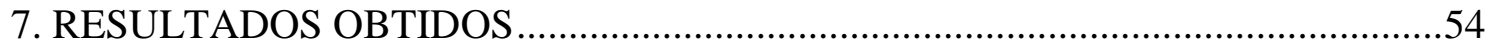

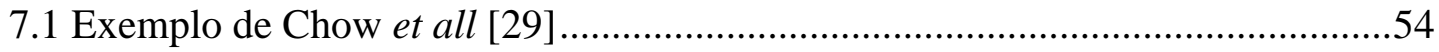

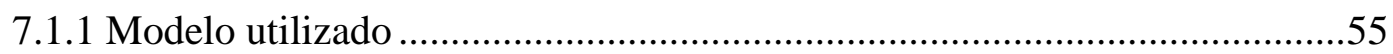

7.1.2 Cálculo do potencial na superfície .......................................................57

7.2 Solo de 2 camadas - Exemplo de Li e Dawalibi ................................................6

7.3 Exemplo de Vujevic e Kurtovic ...............................................................62

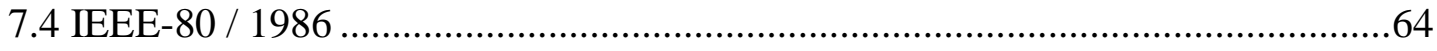

7.4.1 Caso C-4 : 2 camadas com espaçamento uniforme.....................................64

7.4.2 Caso C-6 : Solo uniforme com espaçamento variável .................................67 
7.5 Análise de Sensibilidade da Discretização

.69

8. CONCLUSÃO

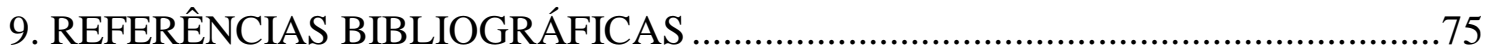


Lista de Símbolos

h : espessura da camada do solo (m)

$\mathrm{H}$ : profundidade do final da camada (m)

I, i : Corrente (A)

$\rho$ : Resistividade do solo $(\Omega . \mathrm{m})$

$\mathrm{P}$ : Posição de um ponto com coordenadas (x, y, z)

r, r' : distância (raio) entre pontos

$\Phi$ : Função potencial (V)

$\sigma:$ Condutividade do solo $(\Omega . m)^{-1}$

$\mathbf{J}:$ Vetor densidade de corrente $\left(\mathrm{A} / \mathrm{m}^{2}\right)$

S, s : Fronteira

f : função que descreve a condição de contorno na fronteira

$\mathrm{V}_{\mathrm{p}}$ : Potencial em um ponto $(\mathrm{V})$

$\mathrm{g}$ : função que descreve as fontes

$\mathrm{G}$ : Função de Green

$\lambda, \mathrm{u}$ : variáveis auxiliares

$\delta$ : Densidade de corrente linear ( A / m)

L : Comprimento de um eletrodo (m)

$R_{i j}$ : Resistência mútua entre elemento i e elemento j $(\Omega)$

$\mathrm{z}_{\mathrm{m}}$ : profundidade média de um eletrodo.

$\mathrm{r}_{\mathrm{h}}$ : raio de uma haste

$\widetilde{\mathrm{G}}$ : Transformada de Fourier da função de Green

a , b : Resíduos e pólos respectivamente de imagens complexas 
F : Função kernel para obtenção da função de Green

$\mathrm{k}_{0}, \mathrm{k}_{\mathrm{z}}, \mathrm{k}_{\mathrm{\rho}}$ : coeficientes de propagação de onda

$\mathrm{J}_{0}$ : Função de Bessel de ordem 0

$\mathrm{r}_{\mathrm{xy}}$; distância entre pontos projetada no plano xy

$\mathrm{k}_{\mathrm{ij}}$ : Coeficiente de reflexão da camada i para camada $\mathrm{j}$

$\mathrm{t}_{\mathrm{ij}}$ : Coeficiente de transmissão da camada i para camada $\mathrm{j}$

$\mathrm{K}_{\mathrm{ij}}$ : Coeficiente de reflexão generalizado da camada i para camada $\mathrm{j}$

$\mathrm{T}_{\mathrm{ij}}$ : Coeficiente de transmissão generalizado da camada i para camada $\mathrm{j}$

$\mathrm{A}_{\mathrm{k}}$ : amplitude do campo na fronteira $\mathrm{k}$ 
Para Paulo Chaves in memoria 


\section{AGRADECIMENTOS}

A meu orientador José Roberto Cardoso pelo contínuo incentivo e pela confiança.

A Ângelo Pássaro e Nancy Abe pelos cálculos com o Ground-3D.

A Júlio Carlos Teixeira pela ajuda na revisão do texto.

A todos os amigos que me concederam apoio e incentivo para a realização deste trabalho. 


\section{RESUMO}

O projeto de malhas de aterramento requer o cálculo da resistência de aterramento e dos potenciais na superfície do solo. Quando o método das imagens é utilizado para este cálculo o modelo típico do solo é uma estratificação horizontal em 2 camadas.

A extensão do método das imagens para solos com múltiplas camadas horizontais apresenta problemas numéricos importantes, de forma que a técnica de imagens complexas foi utilizada para permitir este cálculo, porém restringindo a posição dos eletrodos à primeira camada.

Este trabalho objetiva a aplicação do método de imagens complexas a eletrodos situados em qualquer camada de solos com estratificação horizontal, deduzindo as funções kernel para posições arbitrárias da fonte e do objeto e determinando os resíduos e pólos das imagens utilizando a decomposição em autovalores e autovetores.

Foi desenvolvido um programa que calcula a resistência de aterramento e os potenciais na superfície do solo para solos com até 4 camadas. Foram realizadas comparações com outros trabalhos publicados e os resultados obtidos permitem validar o uso do programa para esta aplicação. 


\begin{abstract}
Ground grid design requests the evaluation of both ground grid resistance and surface voltages. When this evaluation is done using image based methods, the soil model is typically a two-layer horizontally stratified model.
\end{abstract}

Analyzing ground grids buried in horizontally stratified multilayer soil model presents major numerical procedures challenges. Complex image approach allowed some improvement but restricting electrodes position to first layer only.

This work aims modeling ground grid electrodes buried in multilayer horizontally stratified soil model for any position of the buried electrodes, using complex image approach to deduct general kernel functions. The image amplitude and location are determined through an improved Prony method, using singular value technique.

A software package was developed for numerical analysis of ground grid electrodes buried in multilayer horizontally stratified soil model with 4 layer or less. Some ground grids with published results was analyzed and the results validate the developed software package. 


\section{INTRODUÇÃO}

O projeto de malhas de aterramento em baixa freqüência deve considerar dois aspectos básicos, um de desempenho, associado ao valor da resistência de aterramento, e outro de segurança de pessoal, associado à distribuição de potencial na superfície do solo.

Devido às dimensões e complexidade destas malhas este projeto é auxiliado por ferramentas computacionais.

As ferramentas disponíveis no mercado mundial podem ser divididas em dois grandes grupos, um deles utilizando o método dos elementos finitos, com grande flexibilidade para modelar os eletrodos e o solo e mais encontrado em grupos de pesquisas de universidades (Cardoso, J. R. et all, [1] - [3]), e outro utilizando o método das imagens, com maior disseminação entre os projetistas de malhas de aterramento, porém com maiores limitações de modelamento.

Os pacotes computacionais mais conhecidos que utilizam o método das imagens são o SGA do Electric Power Research Institute, o CYMGRD da CYME International e o CEDEGS da Safe Engineering Services \& Technologies. No Brasil a produção de pacotes computacionais desta natureza para uso por projetistas ainda é rara. $\mathrm{O}$ autor desta monografia desenvolveu o código de cálculo do programa Tecat IV [4], que calcula estratificação de solos em até quatro camadas e malhas de aterramento em solos de duas camadas.

Dentre os pacotes citados que utilizam o método das imagens somente o CEDEGS executa cálculos em solos estratificados em mais de duas camadas. Considerando que 
uma estratificação em duas camadas impõe limitações severas no modelo dos solos em análise, é justificável e interessante expandir o domínio de aplicação de técnicas baseadas no Método das Imagens para solos com mais de duas camadas.

Em 1992 Chow e Srivastava [29] apresentaram um trabalho sobre imagens complexas indicando que seria possível superar algumas dificuldades ligadas ao modelamento de malhas em solos estratificados em mais de duas camadas. Caso esta abordagem possa ser utilizada em malhas genéricas, um ganho qualitativo importante pode ser obtido na utilização do Método das Imagens neste tipo de problema.

O objetivo deste trabalho é investigar a aplicação do Método das Imagens ao cálculo de malhas de aterramento utilizando a técnica de imagens complexas, viabilizando a criação de uma ferramenta computacional que permita o cálculo de uma malha de aterramento em solos estratificados horizontalmente em mais de duas camadas.

O Capítulo 2 apresenta uma revisão bibliográfica e o estado da arte para o cálculo de malhas de aterramento utilizando o método das imagens. Não foram considerados métodos baseados em fórmulas aproximadas e, devido à grande quantidade de publicações sobre o tema, são citados apenas os trabalhos pioneiros em cada vertente, ordenados pela data de publicação. As referências bibliográficas no Capítulo 9 estão classificadas pela ordem de citação.

O Capítulo 3 apresenta a formulação geral do problema com ênfase nos aspectos mais fundamentais tal como equações íntegro-diferenciais, hipóteses do modelo utilizado e discretização do domínio. 
O Capítulo 4, sobre a determinação das funções de Green, é o capítulo mais especificamente ligado à técnica das imagens complexas e também onde o autor apresenta sua maior contribuição ao estado da arte da técnica, deduzindo funções de Green para posições arbitrárias da fonte e do objeto em solos estratificados horizontalmente.

O Capítulo 5 mostra as técnicas numéricas para cálculo dos coeficientes das imagens complexas. Neste capítulo o autor introduz uma forma de uso da decomposição em autovalores que aumenta a eficácia e exatidão do método e expande a aplicação das imagens complexas a posições arbitrárias da fonte e do objeto.

O Capítulo 6 aborda os aspectos de implementação computacional descrevendo a arquitetura básica do programa e os principais algoritmos utilizados.

O Capítulo 7 apresenta os resultados obtidos como uma comparação de resultados de cálculo de malhas disponíveis na literatura com os cálculos efetuados pelo programa aqui apresentado. Há também análise de resultados e finalmente a conclusão no capítulo 8. 


\section{ESTADO DA ARTE NO CÁLCULO DE MALHAS DE ATERRAMENTO}

Dwight [5] em 1936 apresentou um método de cálculo de malhas de aterramento de grande porte utilizando o método do potencial médio. Esta abordagem utilizava técnicas de cálculo empregadas na determinação da capacitância de antenas. A distribuição de corrente em cada haste ou cabo era considerada constante.

Em 1953 Gross et all [6] apresentaram o cálculo de uma malha de grande porte, no qual pela primeira vez os eletrodos eram segmentados e a densidade de corrente em cada segmento era calculada. Embora sua formulação fosse limitada a solos uniformes e, conforme os autores, originada do método das sub-áreas de Maxwell, ela já contém todos os elementos básicos utilizados hoje no cálculo de malhas de aterramento pelo Método das Imagens. Em 1963 Thapar e Gross [7] apresentaram uma extensão deste método para um solo de duas camadas com estratificação exponencial.

Em 1964 Tagg [8] analisou mais detalhadamente a resistência de aterramento de eletrodos individuais em solos de duas camadas e em 1965 Sunde [9] apresentou as funções de potencial geradas por uma fonte pontual em solo de $\mathrm{N}$ camadas estratificadas horizontalmente, evidenciando que a dificuldade importante dos solos multicamadas é a integração numérica da função kernel.

Em 1972 Giao e Sarma [10] apresentaram um artigo analisando um eletrodo de aterramento de corrente contínua situado na primeira camada de um solo estratificado em duas camadas horizontais. A análise incluiu a resistência de aterramento e a 
distribuição de potenciais na superfície do solo de um eletrodo formado por cabos retilíneos e em anéis. Toda a abordagem de segmentação de eletrodos e a montagem do sistema matricial para determinação das densidades de corrente já está presente. É apresentada pela primeira vez uma forma geral para funções de potencial de eletrodos não pontuais em solos de duas camadas horizontais.

Entre 1975 e 1979 Dawalibi e Mukhedkar [11] - [17] apresentaram uma série de artigos delineando uma nova forma de abordagem dos problemas de malhas de aterramento onde, embora utilizando as mesmas funções elementares de potencial já vistas em Giao e Sarma, a solução das densidades de corrente não é estabelecida por meio de um sistema matricial mas sim de uma função ponderação dos eletrodos segmentados, evitando o problema de necessidade de memória associado ao método matricial clássico. Esta abordagem originou o programa Malt, precursor do atual CEDEGS da Safe Engineering, permitindo o cálculo de hastes profundas atravessando a interface entre a primeira e a segunda camada. Não foram explicitadas funções de potencial de fontes na segunda camada.

Em 1979 Heppe [18] apresentou um artigo onde foram explicitados as funções de potencial de cabos situados na primeira e segunda camada de solos estratificados em duas camadas horizontais, com solução das densidades de corrente pelo método matricial. O programa Tecat IV [4] utiliza esta formulação proposta por Heppe para o cálculo de malhas.

Em 1980 Kouteynikoff [19] apresentou um novo método de segmentação de eletrodos cilíndricos horizontais denominado microsegmentação, permitindo uma representação 
mais exata de cabos horizontais na análise de malhas de aterramento. Sua aplicação ficou restrita a solos uniformes não ocorrendo desenvolvimentos futuros deste método.

Em 1985 Nagar at all [20] e Loeloeian et all [21] apresentaram uma revisão bibliográfica de métodos de cálculo de malhas de aterramento, comparando as metodologias de Dawalib e Mukhedkar, Heppe e Kouteynikoff. Nesta revisão são explicitadas funções de cálculo de potencial de cabos e fontes situadas em qualquer camada de um solo estratificado em duas camadas horizontais. Verificou-se que os resultados dos três métodos apresentaram boa concordância nos casos estudados.

Ainda em 1985 Garret e Pruitt [22] realizaram uma análise de sensibilidade da abordagem de potencial constante e densidade de corrente variável em eletrodos segmentados, apontando como um fator crítico as dimensões da segmentação utilizada, particularmente nos valores do potencial próximos ao eletrodo. A segmentação também impacta fortemente as dimensões do sistema linear associado, com a correspondente demanda de memória de máquina.

Em 1986 foi publicada a segunda edição do ANSI / IEEE Std 80 [23]. Este guia foi utilizado desde sua primeira edição em 1976 com uma obra de referência para os projetistas da área, utilizando fórmulas aproximadas para o cálculo de resistências e potenciais em solos uniforme. A segunda edição expandiu o domínio de aplicação das fórmulas mantendo a restrição de solo uniforme e inclui o Apêndice $\mathrm{C}$ que, embora não faça parte do corpo do Guia, apresenta resultados de cálculos em solos uniformes e de duas camadas utilizando o programa SGA desenvolvido pelo EPRI. 
Em 1986 Joy e Wilson [24] usaram um programa que utiliza o mesmo algoritmo do SGA do EPRI, realizando uma análise sistemática da exatidão dos resultados em solos estratificados em duas camadas horizontais similar ao de Garret e Pruitt [22], na qual apresentam algumas conclusões sobre a exatidão e domínio de validade do método.

Em 1988 Kovarski et all [25] calcularam o perfil de potenciais gerados por um eletrodo toroidal situado na primeira camada de solos multicamadas. As funções potenciais utilizadas são derivadas do trabalho de Sunde [9]. Os autores expandiram a função kernel da integral em uma somatória de exponenciais, transformando a integração numérica em uma operação analítica. A dificuldade apresentada residiu na determinação dos coeficientes das exponenciais, tarefa que foi realizada com uma abordagem empírica de ajuste de curvas.

Ainda em 1988 Lagace et all [26] estudaram um problema similar ao de Kovarski et all [25], só que utilizando imagens refletidas nas várias interfaces da estratificação do solo. A contribuição de cada imagem foi calculada utilizando coeficientes de transmissão e reflexão semelhantes aos empregados em linhas de transmissão.

Em 1991 Takahashi e Kawase [27] calcularam a resistência de aterramento e o potencial gerado na superfície do solo por uma haste profunda atravessando várias interfaces de um solo multicamada. As funções de potencial foram deduzidas com uma abordagem semelhante à de Sunde mas com todos os potenciais calculados somente na superfície do solo. A integral da função kernel foi efetuada numericamente. 
Ainda em 1991 Dawalibi e Barbeito [28] apresentam pela primeira vez o cálculo de resistências e de potenciais na superfície do solo de uma malha de aterramento em solo multicamadas sem restrição da localização dos eletrodos. A metodologia declarada pelos autores foi inspirada em trabalhos de geofísica e teoria de geração de imagens de óptica. As fórmulas empregadas nas funções potenciais e na geração de imagens não foram explicitadas.

Em 1992 Chow et all [29] aplicam a técnica denominada imagens complexas aos casos estudados por Kovarski et all [25] e Legace et all [26]. Embora apresente semelhança com as expansões exponenciais utilizadas por Kovarski esta abordagem provém da área de microondas, onde os coeficientes e expoentes da série exponencial são associados aos resíduos e pólos da função de transferência do sistema linear, sendo determinados pelo Método de Prony e não por um simples ajuste de curvas. Os exemplos analisados continuam restringindo os eletrodos à primeira camada de um solo multicamadas.

Em 1994 Dawalibi at all [30] publicam uma extensa análise paramétrica de malhas de aterramento em solos estratificados em $\mathrm{N}$ camadas horizontais, demonstrando a robustez dos algoritmos desenvolvidos em [28] e levantando questões de segurança relacionadas a situações de alto contraste de resistividades próximo à superfície do solo. Embora este trabalho não apresente inovações técnicas importantes representou a consolidação do que é hoje o pacote CEDEGS da Safe.

Em 1995 Chow et all [31] demonstram que a partir de medidas do potencial na superfície do solo é possível calcular a resistência de aterramento e a distribuição de potenciais na superfície do solo, sem necessidade de efetuar explicitamente uma 
estratificação do solo convencional, utilizando o método das imagens complexas. Os eletrodos devem estar situados na primeira camada de um modelo de estratificação horizontal em $\mathrm{N}$ camadas.

Ainda em 1995 Elsherbiny et all [32] apresentam um método simplificado de cálculo de aterramento de eletrodos formados apenas por hastes de aterramento em solos de duas camadas, onde cada haste é segmentada em apenas dois segmentos. Esta segmentação simplificada reduz substancialmente a dimensão do sistema linear associado mas só pode ser empregada para o cálculo de resistências.

Em 1997 Li et all [33] apresentam um cálculo de malhas de aterramento utilizando o método proposto por Chow [29] em solos de duas camadas. Apresentam funções potencial para fontes na segunda camada e declaram ter desenvolvido esta formulação também para solos de três camadas. A principal diferença em relação a Chow [28] é que utilizam um algoritmo mais sofisticado para a determinação dos resíduos e pólos da expansão exponencial, permitindo estimar o número $\mathrm{N}$ de termos da expansão.

Em 1998 Vujevic e Kurtovic [34] apresentam um método de cálculo de malhas baseado no método das imagens para solos multicamadas sem restrições da posição dos eletrodos. O princípio básico é a expansão da função kernel em somatória de exponenciais mas, ao invés de imagens complexas utilizou-se uma expansão com até 15 imagens reais. As imagens são calculadas com um algoritmo que realiza amostragem da função kernel em pontos determinados experimentalmente.

A revisão dos trabalhos publicados permite apontar como principais conclusões: 
a) O método matricial com segmentação linear dos eletrodos é utilizado em todas as abordagens para eletrodos de grande porte, pois permite calcular a distribuição de corrente não uniforme entre os eletrodos. A segmentação utilizada tem impacto importante nos erros e no tamanho do sistema linear associado.

b) A tarefa principal na montagem do sistema matricial é a obtenção das resistências mútuas e próprias dos segmentos de eletrodos. É necessário realizar a integral de funções de Green por métodos analíticos ou numéricos.

c) O método das imagens permite representar o problema original por um conjunto de imagens que reproduz o potencial da fonte sobre uma fronteira especificada, tipicamente a superfície dos eletrodos.

d) Para solos de duas camadas a integral é expandida em uma somatória infinita de imagens refletidas nas interfaces. A exatidão da somatória depende do número de termos utilizados que por sua vez é função do coeficiente de reflexão k entre as camadas e da espessura da primeira camada.

e) Para solos multicamadas a expansão em somatória é mais difícil devido à formação de múltiplas seqüências de imagens infinitas. Sintomaticamente os artigos que utilizam esta técnica não explicitam os algoritmos de geração de imagens utilizados.

f) O método das imagens complexas ou imagens equivalentes substitui a somatória de imagens infinitas por um conjunto finito de imagens, quer para um solo de duas 
camadas quer para solos multicamadas, simplificando substancialmente o cálculo das resistências mútuas.

g) O método das imagens complexas para solos multicamadas só é aplicado a eletrodos situados na primeira camada sem uma justificativa explícita para esta limitação. $\mathrm{O}$ domínio do qual é extraída a amostragem para a obtenção das imagens não é discutido explicitamente, dificultando a verificação de resultados. 


\section{FORMULAÇÃO GERAL DO MÉTODO DAS IMAGENS COMPLEXAS PARA SOLOS MULTICAMADAS}

A formulação geral do problema será feita com auxílio do Método dos Momentos e de funções de Green tal como descrito em Sadiku [35].

O problema será apresentado em termos de uma equação diferencial e transformado em uma equação integral.

O domínio será discretizado e as condições de contorno serão utilizadas para montar um sistema matricial cujos coeficientes da matriz serão calculados pelo Método das Imagens. A solução deste sistema será a densidade de corrente em cada região discreta do domínio.

Uma vez conhecidas as densidades de corrente, o potencial em um certo ponto pode ser calculado por integração. 


\subsection{Formulação das equações íntegro-diferenciais}

A Figura 1 mostra uma malha de aterramento constituída por eletrodos cilíndricos imersa em um solo estratificado com $\mathrm{N}$ camadas horizontais.

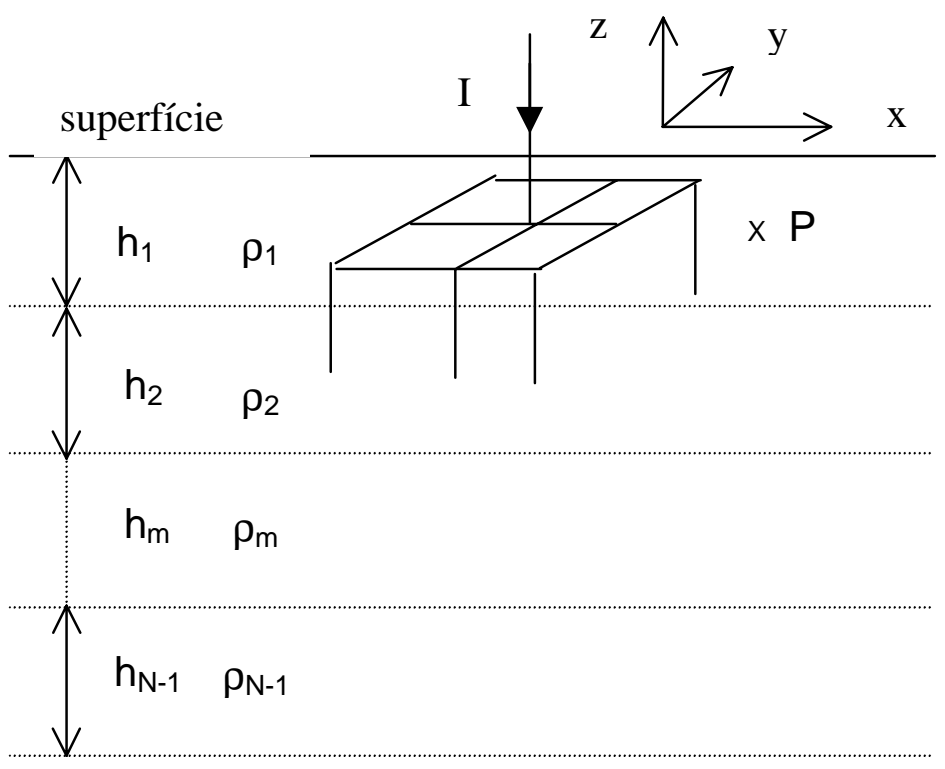

$\rho_{N}$

Figura 1 - Malha de aterramento imersa no solo

A equação geral que descreve este arranjo é:

$\nabla .(\sigma \nabla \Phi)=0$ em todos os pontos exceto no interior dos eletrodos.

$\Phi=f$ sobre a superfície dos eletrodos.

$\iint \vec{J} \cdot d \vec{s}=I$ sobre a superfície dos eletrodos 
Utilizando a função de Green o potencial gerado pela malha em um ponto P será:

$$
V_{p}=\oiiint_{R} g\left(r^{\prime}\right) \cdot G\left(r, r^{\prime}\right) d v^{\prime}
$$

$g\left(r^{\prime}\right)$ representa a distribuição de corrente das fontes e $G\left(r, r^{\prime}\right)$ corresponde à resposta do sistema estimulado por uma função impulso.

\subsection{Discretização do Domínio}

O potencial deve ser determinado na superfície dos eletrodos e no solo, não havendo interesse, neste caso, pelo potencial no interior dos eletrodos.

Hipóteses assumidas para a discretização:

a) A densidade de corrente em cada segmento é constante;

b) A somatória da corrente de cada segmento é igual à corrente injetada I;

c) O potencial sobre a superfície dos segmentos é constante em todo o eletrodo;

d) A distribuição de corrente em eletrodos cilíndricos é simulada por um filete de corrente ao longo do eixo do cilindro.

Considerando as hipóteses, a distribuição de corrente das fontes será nula em todas as regiões exceto no eixo de cada segmento de comprimento $\mathrm{L}_{\mathrm{i}}$, onde terá o valor $\delta_{\mathrm{i}}$. $\mathrm{O}$ potencial gerado por cada segmento em um ponto $\mathrm{P}(\mathrm{r})$ é dado por: 
$\phi_{i}(r)=\int_{L_{i}} \delta_{i} G\left(r, r^{\prime}\right) d r^{\prime}=\frac{i_{i}}{L_{i}} \int_{L_{i}} G\left(r, r^{\prime}\right) d r^{\prime}$

A equação (2) será aproximada por:

$V_{p}=\sum_{i=1}^{N} \frac{i_{i}}{L_{i}} \int_{L_{i}} G\left(r, r^{\prime}\right) d r^{\prime}$

O potencial na superfície de cada segmento j pode ser obtido pela integração de (4) sobre a superfície do segmento. Utilizando a condição de contorno de potencial constante obtém-se:

$\mathrm{V}_{\mathrm{oj}}=\sum_{\mathrm{i}=1}^{\mathrm{N}} \frac{\mathrm{i}_{\mathrm{i}}}{\mathrm{L}_{\mathrm{j}} \cdot \mathrm{L}_{\mathrm{i}}} \int_{\mathrm{L}_{\mathrm{j}} \mathrm{L}_{\mathrm{i}}} \int_{\mathrm{i}} \mathrm{G}\left(\mathrm{r}, \mathrm{r}^{\prime}\right) \mathrm{dr} \mathrm{r}^{\prime} \mathrm{dt}=\sum_{\mathrm{i}=1}^{\mathrm{N}} \mathrm{R}_{\mathrm{ij}} \cdot \mathrm{i}_{\mathrm{i}}$

$R_{i j}$ é a conhecida resistência mútua entre os segmentos i e j.

Uma vez calculados os valores de $R_{i j}$ o sistema de equações lineares em (5) pode ser resolvido obtendo-se a distribuição de correntes $i_{i}$, a qual é utilizada na equação (4) para determinação do potencial em qualquer ponto. 


\subsection{Resistências mútuas de eletrodos lineares}

Os elementos típicos de malhas de aterramento são cabos e hastes. Neste item serão desenvolvidas as fórmulas básicas de resistências mútuas entre estes eletrodos.

\subsubsection{Eletrodos Verticais - Hastes}

A Figura 2 mostra um segmento de haste de comprimento L, situada nas coordenadas $\mathrm{x}_{0}, \mathrm{y}_{0}$ e com profundidade média $\mathrm{z}_{\mathrm{m}}$ injetando uma corrente $\mathrm{I}$ em solo uniforme. Se consideramos um elemento dI da haste o potencial em um ponto $\mathrm{P}(\mathrm{x}, \mathrm{y}, \mathrm{z})$ será:
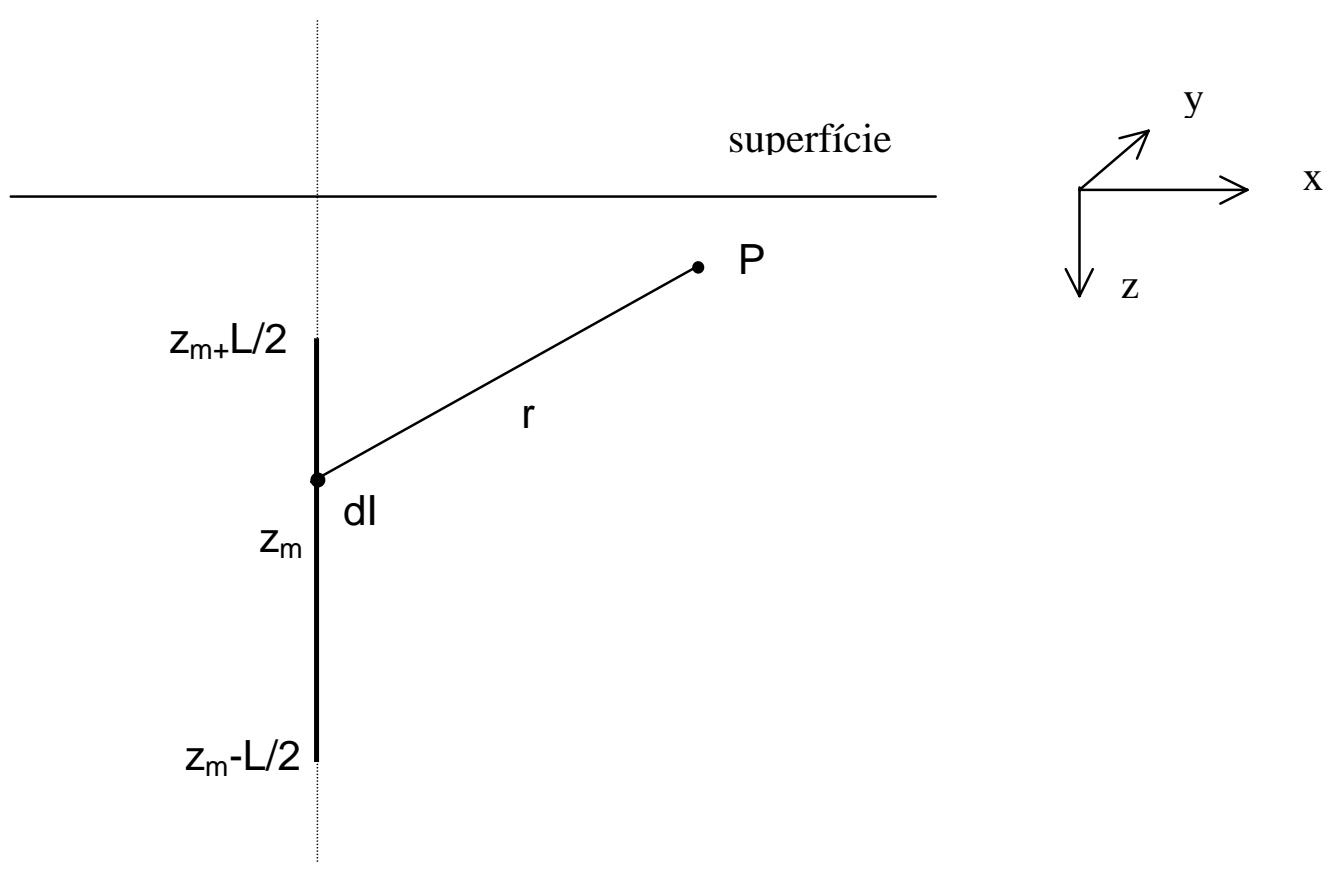

Figura 2 - Haste em solo uniforme 


$$
d V_{p}=\frac{\rho \cdot d I}{4 \pi} \cdot \frac{1}{r}
$$

Se considerarmos o segmento discretizado, tal que a densidade de corrente seja constante $\left(d I=\frac{I}{L} \cdot d z\right)$, o potencial gerado pela haste será:

$$
V_{p}=\frac{\rho . I}{4 \cdot \pi \cdot L} \cdot \int_{-L / 2}^{L / 2} \frac{1}{r} d z=\frac{\rho \cdot I}{4 \pi \cdot L} \cdot \int_{-L / 2}^{L / 2} \frac{1}{\sqrt{\left(x-x_{0}\right)^{2}+\left(y-y_{0}\right)^{2}+\left(z-\left(z_{m}+\lambda\right)\right)^{2}}} d \lambda
$$

fazendo $a^{2}=\left(x-x_{0}\right)^{2}+\left(y-y_{0}\right)^{2}$ e $u=z-\left(z_{m}+\lambda\right)$ então

$$
\begin{aligned}
& \mathrm{V}_{\mathrm{p}}=\frac{-\rho \cdot \mathrm{I}}{4 \cdot \pi \cdot \mathrm{L}} \cdot \int_{\mathrm{u}_{1}}^{\mathrm{u}_{2}} \frac{1}{\sqrt{\mathrm{a}^{2}+\mathrm{u}^{2}} \mathrm{du}=\frac{-\rho \cdot \mathrm{I}}{4 \cdot \pi \cdot \mathrm{L}} \cdot \operatorname{arcsen} \mathrm{h}\left(\frac{\mathrm{u}}{\mathrm{a}}\right)_{\mathrm{u}_{1}}^{\mathrm{u}_{2}}} \\
& \mathrm{~V}_{\mathrm{p}}=\frac{\rho \cdot \mathrm{I}}{4 \cdot \pi \cdot \mathrm{L}} \cdot\left[\operatorname{arcsen} \mathrm{h}\left(\frac{\mathrm{z}-\left(\mathrm{z}_{\mathrm{m}}-\frac{\mathrm{L}}{2}\right)}{\mathrm{a}}\right)-\operatorname{arcsen} \mathrm{h}\left(\frac{\mathrm{z}-\left(\mathrm{z}_{\mathrm{m}}+\frac{\mathrm{L}}{2}\right)}{\mathrm{a}}\right)\right]
\end{aligned}
$$

Esta é a fórmula básica de cálculo do potencial de uma haste em um ponto.

Integrando o valor deste potencial sobre a superfície de uma haste $L_{h}$ situada em $x_{h}, y_{h}$, a uma profundidade média $\mathrm{z}_{\mathrm{mh}}$ e com raio $\mathrm{r}_{\mathrm{h}}$ teremos, denominando $\mathrm{L}_{0}$ o comprimento da haste fonte e $\mathrm{z}_{\mathrm{m} 0}$ a profundidade média: 
$\left.V_{0 h}=\frac{1}{L_{h}} \int_{-L_{h} / 2}^{L_{h} / 2} \frac{\rho . I}{4 \cdot \pi \cdot L_{0}} \cdot \operatorname{arcsen} h\left(\frac{z_{m h}+\lambda-\left(z_{m h}-\frac{L_{h}}{2}\right)}{a}\right)-\operatorname{arcsen} h\left(\frac{z_{m h}+\lambda-\left(z_{m h}+\frac{L_{h}}{2}\right)}{a}\right)\right] d \lambda$

Fazendo $\mathrm{u}=\mathrm{z}_{\mathrm{mh}}+\lambda-\left(\mathrm{z}_{\mathrm{mh}}-\frac{\mathrm{L}_{\mathrm{h}}}{2}\right)$ no primeiro integrando teremos:

$$
f\left(\frac{u}{a}\right)=\int \operatorname{arcsen} h\left(\frac{u}{a}\right) d u=u \cdot \operatorname{arcsen} h\left(\frac{u}{a}\right)-\sqrt{u^{2}+a^{2}}
$$

usando a definição de f(u/a) em (10) então a resistência mútua entre as hastes será:

$$
\begin{aligned}
R_{o h}=\frac{\rho}{4 \cdot \pi \cdot L_{h} \cdot L_{0}} \cdot f\left(\frac{z_{m h}+\frac{L_{h}}{2}-\left(z_{m 0}-\frac{L_{0}}{2}\right)}{a}\right)+ \\
+f\left(\frac{\mathrm{z}_{\mathrm{mh}}-\frac{\mathrm{L}_{\mathrm{h}}}{2}-\left(\mathrm{z}_{\mathrm{m} 0}-\frac{\mathrm{L}_{0}}{2}\right)}{\mathrm{a}}\right)+ \\
+\mathrm{f}\left(\frac{\mathrm{z}_{\mathrm{mh}}+\frac{\mathrm{L}_{\mathrm{h}}}{2}-\left(\mathrm{z}_{\mathrm{m} 0}+\frac{\mathrm{L}_{0}}{2}\right)}{\mathrm{a}}\right)+ \\
\left.+\mathrm{f}\left(\frac{\mathrm{z}_{\mathrm{mh}}-\frac{\mathrm{L}_{\mathrm{h}}}{2}-\left(\mathrm{z}_{\mathrm{m} 0}+\frac{\mathrm{L}_{0}}{2}\right)}{\mathrm{a}}\right)\right]
\end{aligned}
$$

Para calcular a resistência própria de uma haste basta fazer a igual ao raio da haste na fórmula (11). 


\subsubsection{Eletrodos Inclinados ou horizontais - Cabos}

Os cabos serão modelados por segmentos lineares em qualquer ângulo com a superfície exceto verticais, quando se aplica a fórmula anterior para hastes.

A Figura 3 mostra a disposição de um segmento genérico:

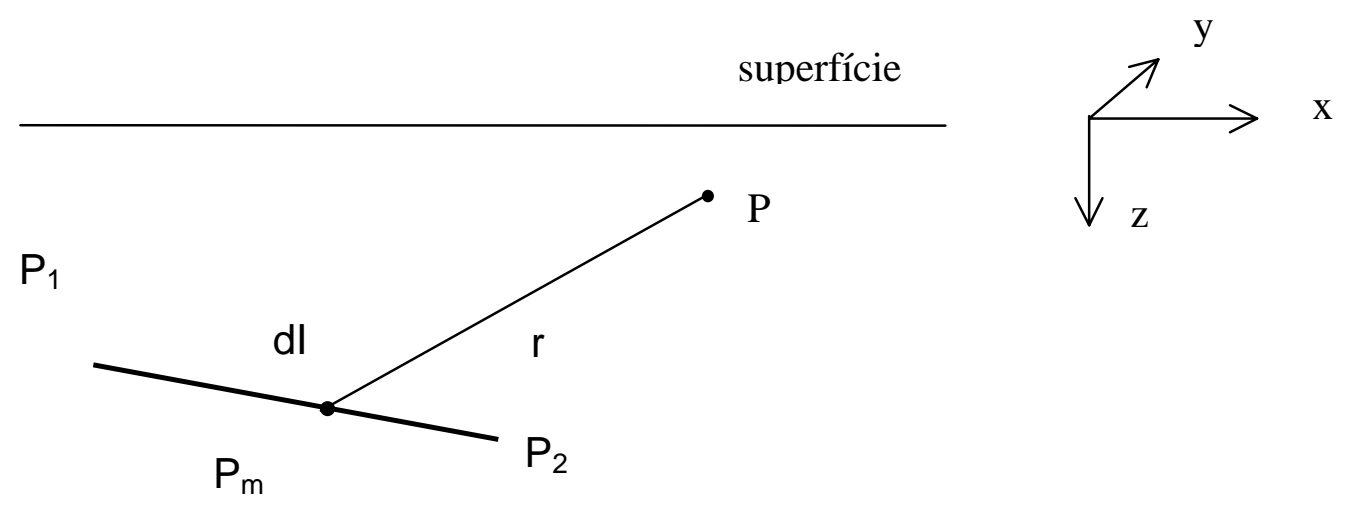

Figura 3 - Cabo inclinado em solo uniforme

Para obtermos o potencial gerado pelo cabo faremos uma integração similar à utilizada para hastes porém empregando uma equação generalizada da reta.

Sendo $\mathrm{P}_{\mathrm{m}}\left(\mathrm{x}_{\mathrm{m}}, \mathrm{y}_{\mathrm{m}}, \mathrm{z}_{\mathrm{m}}\right)$ o ponto médio do cabo e $\Delta \mathrm{x}=\mathrm{x}_{2}-\mathrm{x}_{1}, \Delta \mathrm{y}=\mathrm{y}_{2}-\mathrm{y}_{1}$ e $\Delta \mathrm{z}=\mathrm{z}_{2}-\mathrm{z}_{1}$ então, sendo u uma variável paramétrica $(|\mathrm{u}|<=0,5)$ um ponto arbitrário no cabo pode ser dado por:

$\mathrm{P}(\mathrm{x}, \mathrm{y}, \mathrm{z})=\mathrm{P}_{\mathrm{m}}\left(\mathrm{x}_{\mathrm{m}}, \mathrm{y}_{\mathrm{m}}, \mathrm{z}_{\mathrm{m}}\right)+\mathrm{u} .(\Delta \mathrm{x}, \Delta \mathrm{y}, \Delta \mathrm{z})$ 
Usando as coordenadas em (12) para a integração teremos:

$$
V_{p}=\frac{\rho . I}{4 . \pi} \cdot \int_{-0,5}^{0,5} \frac{1}{\sqrt{\left(x-\left(x_{m}+u . \Delta x\right)\right)^{2}+\left(y-\left(y_{m}+u . \Delta y\right)\right)^{2}+\left(z-\left(z_{m}+u . \Delta z\right)\right)^{2}}} d u
$$

O termo sob a raiz de (13) pode ser posto na forma:

$$
\begin{aligned}
& t=u^{2} \cdot L^{2}+2 \cdot u \cdot\left(\Delta x \cdot\left(x_{m}-x\right)+\Delta y \cdot\left(y_{m}-y\right)+\Delta z \cdot\left(z_{m}-z\right)\right)+\left(x-x_{m}\right)^{2}+\left(z-z_{m}\right)^{2}+\left(z-z_{m}\right)^{2} \\
& t=\frac{1}{L^{2}} \cdot\left(u^{2}+b \cdot u+c\right), \mathrm{com}: \\
& \mathrm{b}=\frac{2}{\mathrm{~L}^{2}} \cdot\left(\Delta \mathrm{x} \cdot\left(\mathrm{x}_{\mathrm{m}}-\mathrm{x}\right)+\Delta \mathrm{y} \cdot\left(\mathrm{y}_{\mathrm{m}}-\mathrm{y}\right)+\Delta \mathrm{z} \cdot\left(\mathrm{z}_{\mathrm{m}}-\mathrm{z}\right)\right) \\
& \mathrm{c}=\frac{1}{\mathrm{~L}^{2}}\left[\left(\mathrm{x}-\mathrm{x}_{\mathrm{m}}\right)^{2}+\left(\mathrm{z}-\mathrm{z}_{\mathrm{m}}\right)^{2}+\left(\mathrm{z}-\mathrm{z}_{\mathrm{m}}\right)^{2}\right] \\
& \text { O potencial será: }
\end{aligned}
$$

$$
\begin{aligned}
& V_{p}=\frac{\rho \cdot I}{4 \cdot \pi \cdot L} \cdot \int_{-0,5}^{0,5} \frac{1}{\sqrt{u^{2}+b \cdot u+c}} d u \\
& V_{p}=\frac{\rho \cdot I}{4 \cdot \pi \cdot L} \cdot \operatorname{arcsen} h\left(\frac{2 \cdot u+b}{4 \cdot c-b^{2}}\right)_{-0,5}^{0,5} \text { ou ainda } \\
& V_{p}=\frac{\rho \cdot I}{4 \cdot \pi \cdot L} \cdot\left[\operatorname{arcsen} h\left(\frac{b+1}{4 \cdot c-b^{2}}\right)-\operatorname{arcsen} h\left(\frac{b-1}{4 \cdot c-b^{2}}\right)\right]
\end{aligned}
$$

A resistência mútua entre cabos e entre cabos e hastes será calculada por integração numérica da fórmula (14). 


\subsection{Introdução de Eletrodos Passivos}

As malhas de aterramento em situações práticas sempre incluem elementos passivos tais como cercas metálicas e eletrodutos no solo. Nestes casos a formulação dada em (5) deve ser alterada para um caso mais genérico tal como descrito em Haffner et all [36].

A equação (5) em forma matricial pode ser colocada como:

$\left[\begin{array}{ccccc}R_{11} & R_{12} & \ldots & R_{1 N-1} & R_{1 N} \\ R_{21} & R_{22} & \ldots & R_{2 N-1} & R_{2 N} \\ \ldots & \ldots & \ldots & \ldots & \ldots \\ R_{N-1,1} & R_{N-1,2} & \ldots & R_{N-1, N-1} & R_{N-1, N} \\ R_{N 1} & R_{N 2} & \ldots & R_{N N-1} & R_{N N}\end{array}\right] \cdot\left[\begin{array}{c}i_{1} \\ i_{2} \\ \ldots \\ i_{N-1} \\ i_{N}\end{array}\right]=\left[\begin{array}{c}V_{0} \\ V_{0} \\ \ldots \\ V_{0} \\ V_{0}\end{array}\right]$

Mais a condição de contorno adicional para as correntes :

$\sum_{k=1}^{N} i_{k}=-I$

Se agruparmos as fórmulas (15) e (16) teremos:

$\left[\begin{array}{cccccc}R_{11} & R_{12} & \ldots & R_{1 N-1} & R_{1 N} & -1 \\ R_{21} & R_{22} & \ldots & R_{2 N-1} & R_{2 N} & -1 \\ \ldots & \ldots & \ldots & \ldots & \ldots & \ldots \\ R_{N-1,1} & R_{N-1,2} & \ldots & R_{N-1, N-1} & R_{N-1, N} & -1 \\ R_{N 1} & R_{N 2} & \ldots & R_{N N-1} & R_{N N} & -1 \\ -1 & -1 & \ldots & -1 & -1 & 0\end{array}\right] \cdot\left[\begin{array}{c}i_{1} \\ i_{2} \\ \ldots \\ i_{N-1} \\ i_{N} \\ V_{0}\end{array}\right]=\left[\begin{array}{c}0 \\ 0 \\ \ldots \\ 0 \\ 0 \\ -I\end{array}\right]$ 
A matriz [R] é simétrica, pois $\mathrm{R}_{\mathrm{ij}}=\mathrm{R}_{\mathrm{ji}}$.

Observar que a tensão $\mathrm{V}_{0}$ é agora uma das incógnitas do sistema, pois conhecemos de fato a corrente de curto-circuito na subestação e não o potencial médio nos eletrodos.

Para introduzirmos eletrodos passivos basta observar que a somatória das correntes dos segmentos do eletrodo é nula. Usando o índice a para eletrodo ativo e p para passivo teremos:

$$
\left[\begin{array}{cccccccc}
R_{a 11} & \ldots & R_{a 1 N a} & R_{a p 11} & \ldots & R_{a p 1 N p} & -1 & 0 \\
\ldots & \ldots & \ldots & \ldots & \ldots & \ldots & \ldots & \ldots \\
R_{a N a 1} & \ldots & R_{a N N a} & R_{a p N a 1} & \ldots & R_{a p N a N p} & -1 & 0 \\
R_{p a 11} & \ldots & R_{p a 1 N a} & R_{p 11} & \ldots & R_{p 1 N p} & 0 & -1 \\
\ldots & \ldots & \ldots & \ldots & \ldots & \ldots & \ldots & \ldots \\
R_{p a N p 1} & \ldots & R_{p a N p N a} & R_{p N p 1} & \ldots & R_{p N p N p} & 0 & -1 \\
-1 & \ldots & -1 & 0 & \ldots & 0 & 0 & 0 \\
0 & \ldots & 0 & -1 & \ldots & -1 & 0 & 0
\end{array}\right] \cdot\left[\begin{array}{c}
i_{a 1} \\
\ldots \\
i_{a N a} \\
i_{p 1} \\
\ldots \\
i_{p N p} \\
V_{a} \\
V_{p}
\end{array}\right]=\left[\begin{array}{c}
0 \\
\ldots \\
0 \\
0 \\
\ldots \\
0 \\
-I_{a} \\
0
\end{array}\right]
$$

Obteremos como solução da equação (18) a corrente em cada segmento dos eletrodos ativos e passivos e os potenciais nos dois eletrodos, permitindo, por exemplo, o cálculo da diferença de potencial entre a cerca e a malha.

Veremos no próximo capítulo a dedução das funções $G\left(r, r^{\prime}\right)$ da equação (4) e a solução da integral pelo método das imagens complexas. 


\section{DETERMINAÇÃO DAS FUNÇÕES DE GREEN}

A função de Green $G\left(r, r^{\prime}\right)$ representa a resposta do sistema a uma fonte impulsiva. Para um campo de correntes estacionárias é a função potencial gerada por uma carga pontual. O potencial de uma fonte pontual de corrente I, situada na origem em um solo homogêneo sem fronteiras, pode ser calculado integrando-se a densidade de corrente sobre uma superfície esférica a uma distância $r$ da fonte e aproveitando a simetria esférica :

$I=\iint_{S} \mathbf{J} \cdot d \mathbf{s}=J .4 \pi r^{2}$ ou $J=\frac{I}{4 \pi r^{2}}$

a função de Green será :

$G(r)=-\int_{r}^{\infty} \rho . J d r^{\prime}=\frac{\rho I}{4 \pi r}$

Para um solo estratificado em N camadas horizontais não é possível uma integração analítica simples como a de (19) e (20) e será necessário o uso de abordagens mais genéricas como a utilizada por Chew [37].

\subsection{Fonte pontual em meio homogêneo}

Supondo uma fonte de corrente pontual situada na origem o potencial gerado em um ponto r será, usando a identidade de Sommerfeld: 
$V(r)=\frac{I \rho}{4 \pi} e^{i k_{0} r}=\frac{I \rho}{4 \pi} i \int_{0}^{\infty} \frac{k_{\rho}}{k_{z}} J_{0}\left(k_{\rho} \rho\right) e^{i k_{z}|z|} d k_{\rho}$

onde $k_{\rho}$ e $k_{z}$ são os coeficientes de propagação na direção radial e de $z$ respectivamente e $k_{0}^{2}=k_{\rho}^{2}+k_{z}^{2}$.

Os estudos de propagação de onda feitos por Chew são voltados para a área de microondas, onde o principal componente dos campos está ligado à variação com o tempo. As fórmulas deverão ser adaptadas para o caso de campo de correntes de frequiência nula ou muita baixa, como é o caso do presente estudo.

Para o caso de freqüência nula o número de onda $\mathrm{k}_{0}$ é igual a zero. Assumindo que a fonte está em uma posição x', y', z' teremos que o potencial em um ponto x, y, z:

$$
\begin{aligned}
& k_{\rho}^{2}+k_{z}^{2}=0 \rightarrow k_{z}=\sqrt{-k_{\rho}^{2}} \rightarrow k_{z}=i \cdot k_{\rho}, \text { substituindo em }(21): \\
& V(\rho, z)=\frac{I \rho}{4 \pi} i \int_{0}^{\infty} \frac{k_{\rho}}{i . k_{\rho}} J_{0}(\lambda \rho) e^{i \cdot\left(i . k_{\rho}\right) \cdot\left|z-z^{\prime}\right|} d k_{\rho}
\end{aligned}
$$

Utilizando a variável de integração $\lambda=k_{\rho}$ teremos:

$$
V\left(r_{x y}, z\right)=\frac{I \rho}{4 \pi} \int_{0}^{\infty} J_{0}\left(\lambda r_{x y}\right) e^{-\lambda\left|z-z^{\prime}\right|} \quad, \operatorname{com} r_{x y}=\sqrt{\left(x-x^{\prime}\right)^{2}+\left(y-y^{\prime}\right)^{2}}
$$


A função $F\left(z, z^{\prime}\right)=e^{-\lambda\left|z-z^{\prime}\right|}$ é a função kernel desta integral, e depende apenas dos parâmetros do solo e da posição da fonte e do objeto.

Efetuando esta integral obteremos novamente:

$V(r)=\frac{I \rho}{4 \pi} \frac{1}{\sqrt{\left(x-x^{\prime}\right)^{2}+\left(y-y^{\prime}\right)^{2}+\left(z-z^{\prime}\right)^{2}}}=\frac{I \rho}{4 \pi r}$

Se a fonte estiver em um semiespaço, tal como o de um solo uniforme, basta somarmos a imagem substituindo $\left(z-z^{\prime}\right)^{2}$ por $\left(z+z^{\prime}\right)^{2}$ em (23).

\subsection{Fonte pontual em meio estratificado horizontalmente, fonte e objeto na mesma camada}

A Figura 4 mostra uma fonte pontual A imersa em uma camada $\mathrm{m}$ de um solo estratificado em $\mathrm{N}$ camadas horizontais e um ponto objeto $\mathrm{P}$, situado na mesma camada m, com o eixo z com origem na superfície e orientado para cima:

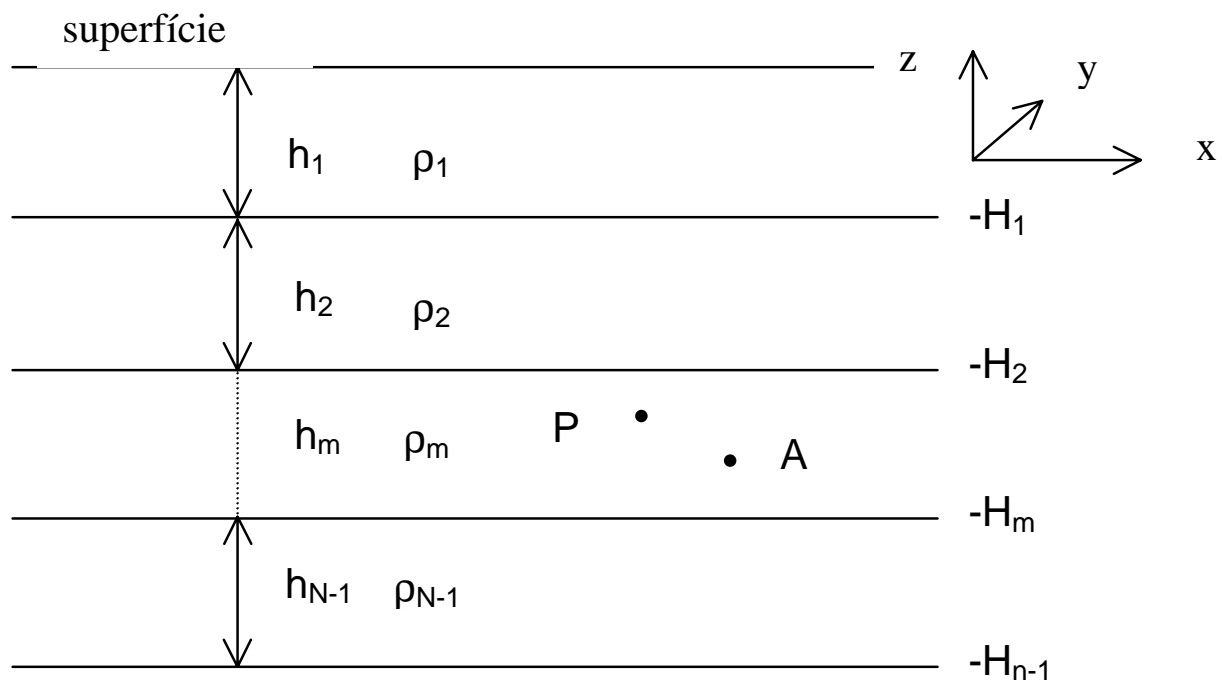

$\rho_{N}$

Figura 4- Fonte pontual na camada $\mathrm{m}$ de um solo estratificado 
Observar que o ar constitui a primeira camada nesta formulação, $\operatorname{com} \rho_{\mathrm{ar}}=\infty$, e o número de camadas total é $\mathrm{M}=\mathrm{N}+1$.

A solução do potencial terá a forma:

$$
V\left(r, z, z^{\prime}\right)=\frac{I \rho}{4 \pi} \int_{0}^{\infty} J_{0}(\lambda r) F\left(z, z^{\prime}\right) d \lambda
$$

A solução deverá atender às condições de contorno:

- Corrente na direção z na superfície é nula: $\left.\frac{\partial V}{\partial z}\right|_{z=0}=0$

- O potencial é contínuo em cada interface.

- O componente normal da densidade corrente é contínuo em cada interface:

$$
\left.\frac{1}{\rho_{i}} \frac{\partial V}{\partial z}\right|_{z=h_{i}}=\left.\frac{1}{\rho_{i+1}} \frac{\partial V}{\partial z}\right|_{z=h_{i}}
$$

Chew [37] resolve este problema utilizando abordagem de propagação de ondas entre as camadas, lançando mão de coeficientes generalizados de reflexão e transmissão.

A solução geral para a equação (24) em cada camada será dada pela soma do efeito da fonte em meio uniforme mais o efeito de ondas viajantes:

$$
V_{i}\left(r, z, z^{\prime}\right)=\frac{I \rho_{m}}{4 \pi} \int_{0}^{\infty} J_{0}(\lambda r) F_{m i}\left(z, z^{\prime}\right) d \lambda, \text { com }
$$


$F_{m i}\left(z, z^{\prime}\right)=e^{-\lambda\left|z-z^{\prime}\right|}+B_{m} e^{\lambda z}+D_{m} e^{-\lambda z}$

$\mathrm{O}$ coeficiente $\mathrm{B}_{\mathrm{m}}$ está associado à reflexão do campo na fronteira $\mathrm{H}_{\mathrm{m}-1}$ e o coeficiente $\mathrm{D}_{\mathrm{m}}$ à fronteira $\mathrm{H}_{\mathrm{m}}$. Para explicitarmos a solução utilizaremos coeficientes de reflexão e transmissão generalizados.

\subsubsection{Coeficientes de Reflexão e Transmissão}

Sendo $\rho_{\mathrm{i}-1}, \rho_{\mathrm{i}}, \rho_{\mathrm{i}+1}$ as resistividades de 3 camadas adjacentes Chew define os coeficientes:

a) Coeficiente de reflexão visto da camada $\mathrm{i}$

ascendente : $k_{i, i-1}=k_{-i}=\frac{\rho_{i-1}-\rho_{i}}{\rho_{i-1}+\rho_{i}}$, descendente: $k_{i, i+1}=k_{+i}=\frac{\rho_{i+1}-\rho_{i}}{\rho_{i+1}+\rho_{i}}$

b) Coeficiente de transmissão visto da camada i para a camada $\mathrm{j}$ $\mathrm{t}_{\mathrm{i}, \mathrm{j}}=1+\mathrm{k}_{\mathrm{i}, \mathrm{j}}$

c) Coeficiente de reflexão generalizado visto da camada $\mathrm{i}$

Estes coeficientes são calculados de forma recursiva: 


$$
\begin{gathered}
K_{i, i-1}=K_{-i}=1, \text { se } \mathrm{i}=2 \text {, senão } \\
\frac{k_{-i}+K_{-(i-1)} e^{-2 \lambda h_{i-1}}}{1+k_{-i} K_{-(i-1)} e^{-2 \lambda h_{i-1}}} \\
K_{i, i+1}=K_{+i}=0, \text { se } \mathrm{i}=M \text {, senão } \\
\frac{k_{+i}+K_{+(i+1)} e^{-2 \lambda h_{i+1}}}{1+k_{+i} K_{+(i+1)} e^{-2 \lambda h_{i+1}}}
\end{gathered}
$$

\subsubsection{Solução para a função kernel}

Devemos utilizar as condições de fronteira para determinar Bm e Dm. Olhando na Figura 4 podemos observar que a onda descendente entre o ponto $\mathrm{P}$ e a fronteira $\mathrm{H}_{\mathrm{m}-1}$ é totalmente devida à reflexão da onda ascendente na fronteira $\mathrm{H}_{\mathrm{m}-1}$ :

$B_{m} \cdot e^{-\lambda \cdot H_{m-1}}=K_{m, m-1} \cdot\left[e^{-\lambda \cdot\left|H_{m-1}+z^{\prime}\right|}+D_{m} \cdot e^{\lambda \cdot H_{m-1}}\right]$

Analogamente a onda ascendente entre $\mathrm{P}$ e a fronteira $\mathrm{H}_{\mathrm{m}}$ é totalmente devida à reflexão da onda descendente na fronteira $\mathrm{H}_{\mathrm{m}}$ :

$D_{m} \cdot e^{\lambda \cdot H_{m}}=K_{m, m+1} \cdot\left[e^{-\lambda \cdot\left|H_{m}+z^{\prime}\right|}+B_{m} \cdot e^{-\lambda \cdot H_{m}}\right]$

Resolvendo para $\mathrm{F}_{\mathrm{m}}$ obtemos:

$\left.F_{m+}\left(z, z^{\prime}\right)=\left\lfloor e^{\lambda z^{\prime}}+e^{-\lambda\left(z^{\prime}+2 H m\right)} K_{m, m+1}\right\rfloor e^{-\lambda z}+e^{\lambda(z+2 H m-1)} K_{m, m-1}\right\rfloor M_{m}$, se z > z' 


$$
\left.F_{m-}\left(z, z^{\prime}\right)=\left\lfloor e^{-\lambda z^{\prime}}+e^{\lambda\left(z^{\prime}+2 H m-1\right)} K_{m, m-1}\right\rfloor \mid e^{\lambda z}+e^{-\lambda(z+2 H m)} K_{m, m+1}\right\rfloor M_{m}, \text { se z<z' }
$$

$$
M_{m}=\frac{1}{1-K_{m, m+1} K_{m, m-1} e^{-2 \lambda h_{m}}}, H_{m}=\sum_{i=1}^{m} h_{i}
$$

Utilizando a função módulo as fórmulas (30) e (31) podem ser agrupadas em

$$
\begin{aligned}
F_{m m}\left(z, z^{\prime}\right)= & \mid e^{-\lambda\left|z-z^{\prime}\right|}+K_{m, m+1} e^{-\lambda\left(z+z^{\prime}+2 H_{m}\right)}+K_{m, m-1} e^{\lambda\left(z+z^{\prime}+2 H_{m-1}\right)}+ \\
& +K_{m, m+1} K_{m, m-1} e^{-\lambda\left(2 h_{m}-\mid z-z^{\prime}\right)} \mid M_{m}
\end{aligned}
$$

Observar que existe a propriedade de simetria na função $F_{m m}$, ou seja :

$$
F_{m m}\left(z, z^{\prime}\right)=F_{m m}\left(z^{\prime}, z\right)
$$

\subsection{Fonte pontual em meio estratificado horizontalmente, fonte e objeto em camadas diferentes}

Suponhamos agora que na Figura 4 o ponto $\mathrm{P}$ está em uma camada $\mathrm{n}$ acima da camada $m$ da fonte. Neste caso, se o campo na fronteira $H_{n}$ for $A_{n}$ então no ponto $P$ será:

$$
F(z)=A_{n} \cdot\left(e^{-\lambda \cdot z}+K_{n, n-1} \cdot e^{2 \cdot \lambda \cdot H_{n-1}+\lambda \cdot z}\right)
$$

Será necessário a determinação de $\mathrm{A}_{\mathrm{n}}$ a partir do valor do campo na região $\mathrm{n}$. Para isto usaremos a fórmula de recursão entre meios contíguos: 
$A_{i}=A_{i+1} \cdot \frac{t_{i+1, i}}{1+k_{i, i+1} \cdot K_{i, i-1} \cdot e^{-2 \cdot \lambda \cdot\left(H_{i}-H_{i-1}\right)}}$

Definindo $S_{i+1, i}=\frac{t_{i+1, i}}{1+k_{i, i+1} \cdot K_{i, i-1} \cdot e^{-2 . \lambda .\left(H_{i}-H_{i-1}\right)}}$ então:

$A_{i}=A_{i+1} \cdot S_{i+1, i}$

A fórmula (35) coloca o valor do campo na camada i em função do valor do campo na camada imediatamente abaixo i+1. Usando esta fórmula recursivamente desde a camada $\mathrm{m}$ até a $\mathrm{n}$ teremos:

$A_{n}=S_{n+1, n} \cdot S_{n+2, n+1} \cdots S_{m-1, m-2} \cdot S_{m, m-1} \cdot A_{m}$ ou

$A_{n}=A_{m} \cdot \prod_{j=n}^{m-1} S_{m, m-1}$

Mas o valor de $\mathrm{A}_{\mathrm{m}}$ é dado pelo primeiro termo entre colchetes da fórmula (30), daí:

$F_{m>n}\left(z, z^{\prime}\right)=\left[e^{\lambda z^{\prime}}+K_{m, m+1} \cdot e^{-\lambda\left(z^{\prime}+2 H m\right)}\right]\left[e^{-\lambda z}+K_{n, n-1} \cdot e^{\lambda(z+2 H n-1)}\right] M_{m} \cdot \prod_{\mathrm{j}=\mathrm{n}}^{\mathrm{m}-1} \mathrm{~S}_{\mathrm{j}+1, \mathrm{j}}$

Utilizando o mesmo raciocínio para o ponto $\mathrm{P}$ situado em uma camada $\mathrm{n}$ abaixo da camada $m$ da fonte teremos:

$$
F_{m<n}\left(z, z^{\prime}\right)=\left[e^{\lambda z}+K_{n, n+1} \cdot e^{-\lambda(z+2 H n)}\right]\left[e^{-\lambda z^{\prime}}+K_{m, m-1} \cdot e^{\lambda\left(z^{\prime}+2 H m-1\right)}\right] M_{m} \cdot \prod_{\mathrm{j}=m}^{\mathrm{n}-1} \mathrm{~S}_{\mathrm{j}, \mathrm{j}+1}
$$


Novamente podemos observar a simetria entre as fórmulas (37) e (38).

\subsection{Solução por integração direta}

Fazendo a substituição das funções kernel na função potencial (25) pode-se observar que não é possível efetuar integração analítica direta exceto para o caso de 2 camadas, quando as fórmulas da função kernel degeneram.

Para o caso de 2 camadas teremos, para o caso da fonte e objeto na primeira camada:

$\mathrm{K}_{\mathrm{m}, \mathrm{m}-1}=1$, pois a resistividade do ar é considerada infinita.

$\mathrm{K}_{\mathrm{m}, \mathrm{m}+1}=\mathrm{k}_{12}=\mathrm{k}=\frac{\rho_{2}-\rho_{1}}{\rho_{2}+\rho_{1}}:$ fator de reflexão

$\mathrm{H}_{\mathrm{m}}=\mathrm{h}_{1}=\mathrm{h}$ : espessura da primeira camada

$\mathrm{H}_{\mathrm{m}-1}=0$

$M_{m}=\frac{1}{1-k \cdot e^{-2 \cdot \lambda \cdot h_{1}}}$

A fórmula (32) será simplificada para:

$F_{11}\left(z, z^{\prime}\right)=\frac{e^{-\lambda\left|z-z^{\prime}\right|}+k \cdot e^{-\lambda\left(z+z^{\prime}+2 . h\right)}+e^{\lambda\left(z+z^{\prime}\right)}+k \cdot e^{-\lambda\left(2 \cdot h-\mid z-z^{\prime}\right)}}{1-k \cdot e^{-2 \cdot \lambda \cdot h}}$

rearranjando: 
$F_{11}\left(z, z^{\prime}\right)=\frac{\left(e^{-\lambda\left|z-z^{\prime}\right|}+e^{\lambda\left(z+z^{\prime}\right)}\right) \cdot\left(1-k \cdot e^{-2 \cdot \lambda \cdot h}\right)+k \cdot e^{-2 \cdot \lambda \cdot h} \cdot\left(e^{-\lambda\left|z-z^{\prime}\right|}+e^{-\lambda\left(z+z^{\prime}\right)}+e^{\lambda\left(z+z^{\prime}\right)}+e^{\lambda \cdot\left|z-z^{\prime}\right|}\right)}{1-k \cdot e^{-2 \cdot \lambda \cdot h}}$

extraindo o termo da fonte e da primeira imagem refletida na superfície do solo:

$F_{11}\left(z, z^{\prime}\right)=e^{-\lambda\left|z-z^{\prime}\right|}+e^{\lambda\left(z+z^{\prime}\right)}+\frac{k \cdot e^{-2 . \lambda . h} \cdot\left(e^{-\lambda\left|z-z^{\prime}\right|}+e^{-\lambda\left(z+z^{\prime}\right)}+e^{\lambda\left(z+z^{\prime}\right)}+e^{\lambda \cdot\left|z-z^{\prime}\right|}\right)}{1-k \cdot e^{-2 . \lambda . h}}$

O termo fracionário de (40) pode ser posto na forma:

$t f_{11}\left(z, z^{\prime}\right)=\frac{k \cdot e^{-2 . \lambda \cdot h}}{1-k \cdot e^{-2 . \lambda . h}} \cdot\left(e^{-\lambda\left|z-z^{\prime}\right|}+e^{-\lambda\left(z+z^{\prime}\right)}+e^{\lambda\left(z+z^{\prime}\right)}+e^{\lambda \cdot\left|z-z^{\prime}\right|}\right)$

mas $|x|=\left|k \cdot e^{-2 . \lambda \cdot h}\right| \leq 1$, daí podemos expandir

$\frac{k \cdot e^{-2 . \lambda \cdot h}}{1+\left(-k \cdot e^{-2 . \lambda \cdot h}\right)}=k \cdot e^{-2 \cdot \lambda \cdot h} \cdot\left[1-\left(-k \cdot e^{-2 \cdot \lambda \cdot h}\right)+\left(-k \cdot e^{-2 . \lambda \cdot h}\right)^{2}-\left(-k \cdot e^{-2 . \lambda \cdot h}\right)^{3}+\ldots\right]$

$\frac{k \cdot e^{-2 \cdot \lambda \cdot h}}{1+\left(-k \cdot e^{-2 \cdot \lambda \cdot h}\right)}=\sum_{j=1}^{\infty} k^{n} \cdot e^{-2 \cdot n \cdot h \cdot \lambda}$

Substituindo (40) e (41) em (25) teremos a função potencial:

$V_{1}\left(r_{x y}, z, z^{\prime}\right)=\frac{I \rho_{1}}{4 \pi} \int_{0}^{\infty} J_{0}\left(\lambda r_{x y}\right) \cdot\left[e^{-\lambda\left|z-z^{\prime}\right|}+e^{\lambda\left(z+z^{\prime}\right)}+\right.$ 
$\left.+\left(\sum_{j=1}^{\infty} k^{n} \cdot e^{-2 \cdot n \cdot h \cdot \lambda}\right) \cdot\left(e^{-\lambda\left|z-z^{\prime}\right|}+e^{-\lambda\left(z+z^{\prime}\right)}+e^{\lambda\left(z+z^{\prime}\right)}+e^{\lambda \cdot\left|z-z^{\prime}\right|}\right)\right] d \lambda$

$\operatorname{Mas} \int_{0}^{\infty} J_{0}(\lambda \cdot b) \cdot e^{-\lambda \cdot a}=\frac{1}{\sqrt{a^{2}+b^{2}}}$, portanto:

$$
\begin{aligned}
& V_{1}\left(r_{x y}, z, z^{\prime}\right)=\frac{I \rho_{1}}{4 \pi} \cdot\left[\frac{1}{\sqrt{r_{x y}^{2}+\left(z-z^{\prime}\right)^{2}}}+\frac{1}{\sqrt{r_{x y}^{2}+\left(z+z^{\prime}\right)^{2}}}+\right. \\
& \sum_{j=1}^{\infty} k^{n} \cdot\left(\frac{1}{\sqrt{r_{x y}^{2}+\left(\left|z-z^{\prime}\right|+2 n h\right)^{2}}}+\frac{1}{\sqrt{r_{x y}^{2}+\left(z+z^{\prime}+2 n h\right)^{2}}}+\right. \\
& \left.\left.+\frac{1}{\sqrt{r_{x y}^{2}+\left(z+z^{\prime}-2 n h\right)^{2}}}+\frac{1}{\sqrt{r_{x y}^{2}+\left(\left|z-z^{\prime}\right|-2 n h\right)^{2}}}\right)\right]
\end{aligned}
$$

A fórmula (42) é citada em todas as abordagens de imagens em solos de duas camadas. 
A Figura 5 mostra a representação física da fórmula (42) com o posicionamento das imagens:

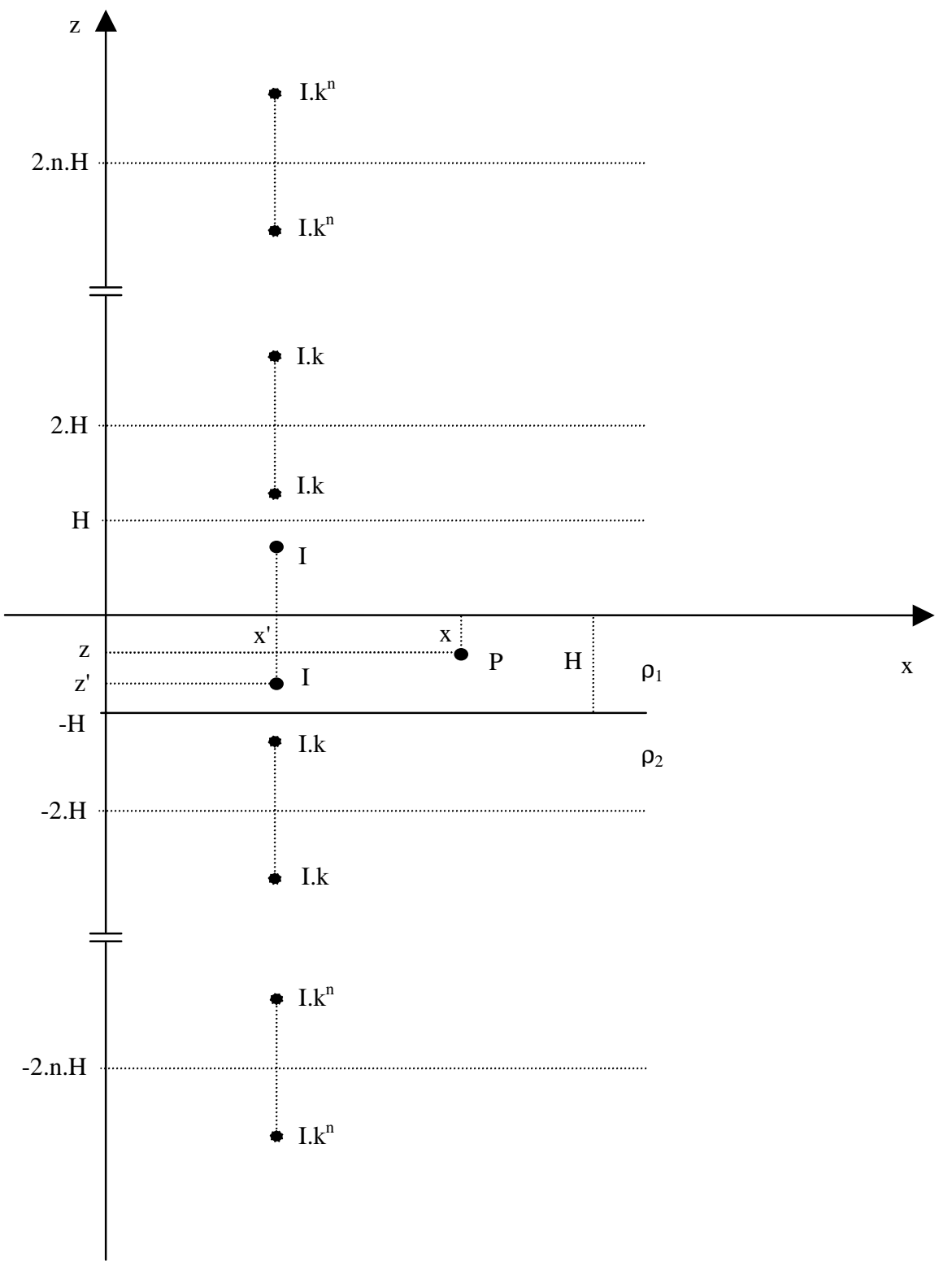

Figura 5- Reflexões de uma fonte em solos de duas camadas

Para solos com mais de duas camadas cada uma das imagens da Figura 5 provoca novas reflexões nas outras interfaces entre camadas tornando o método inviável. A integral 
deve então ser obtida através de técnicas numéricas tal como a de imagens complexas que será apresentada no próximo capítulo. 


\section{IMAGENS COMPLEXAS}

A técnica de imagens complexas foi empregada pela primeira vez em sistemas de aterramento por Chow et all [29] para obter a função de Green a partir da integral da função kernel.

\subsection{Imagens Complexas tal como apresentadas por Chow et all [29]}

A inovação apresentada por Chow em [29] foi a de utilizar a transformada de Fourier da função de Green em (5) na forma:

$\tilde{G}=\frac{\rho . d i}{2 \gamma}\left[e^{-\gamma\left(z-z^{\prime}\right)}+e^{-\gamma\left(z+z^{\prime}\right)}-\frac{R(\gamma)}{1+R(\gamma) e^{-\gamma h_{1}}} S_{\exp }\right]$

com:

$S_{\exp }=e^{-\gamma\left(z-\left(z^{\prime}-2 h_{1}\right)\right)}+e^{-\gamma\left(z+\left(z^{\prime}+2 h_{1}\right)\right)}+e^{-\gamma\left(z+\left(z^{\prime}-2 h_{1}\right)\right)}+e^{-\gamma\left(z-\left(z^{\prime}+2 h_{1}\right)\right)}$

A fórmula (43) é válida para a fonte localizada na primeira camada e é expandida numa somatória de exponenciais, podendo tomar duas formas:

a) Profundidades da fonte e do ponto de cálculo constantes:

A expansão será

$\frac{R(\gamma)}{1+R(\gamma) e^{-\gamma h_{1}}} S_{\exp }=\sum_{i=1}^{N} a_{i} e^{b_{i} \gamma}$ 
Substituindo (44) em (43) e aplicando a transformada inversa obtemos a função de Green:

$G=\frac{\rho I}{4 \pi}\left[\frac{1}{r_{0}}+\frac{1}{r_{0}^{\prime}}+\sum_{i=1}^{N} \frac{a_{i}}{r_{i}}\right]$

com:

$$
\begin{aligned}
& r_{0}=\sqrt{\left(x-x^{\prime}\right)^{2}+\left(y-y^{\prime}\right)^{2}+\left(z-z^{\prime}\right)^{2}}, r_{0}^{\prime}=\sqrt{\left(x-x^{\prime}\right)^{2}+\left(y-y^{\prime}\right)^{2}+\left(z+z^{\prime}\right)^{2}} \\
& r_{i}=\sqrt{\left(x-x^{\prime}\right)^{2}+\left(y-y^{\prime}\right)^{2}+b_{i}^{2}}
\end{aligned}
$$

A Figura 6 mostra a disposição esquemática das imagens:

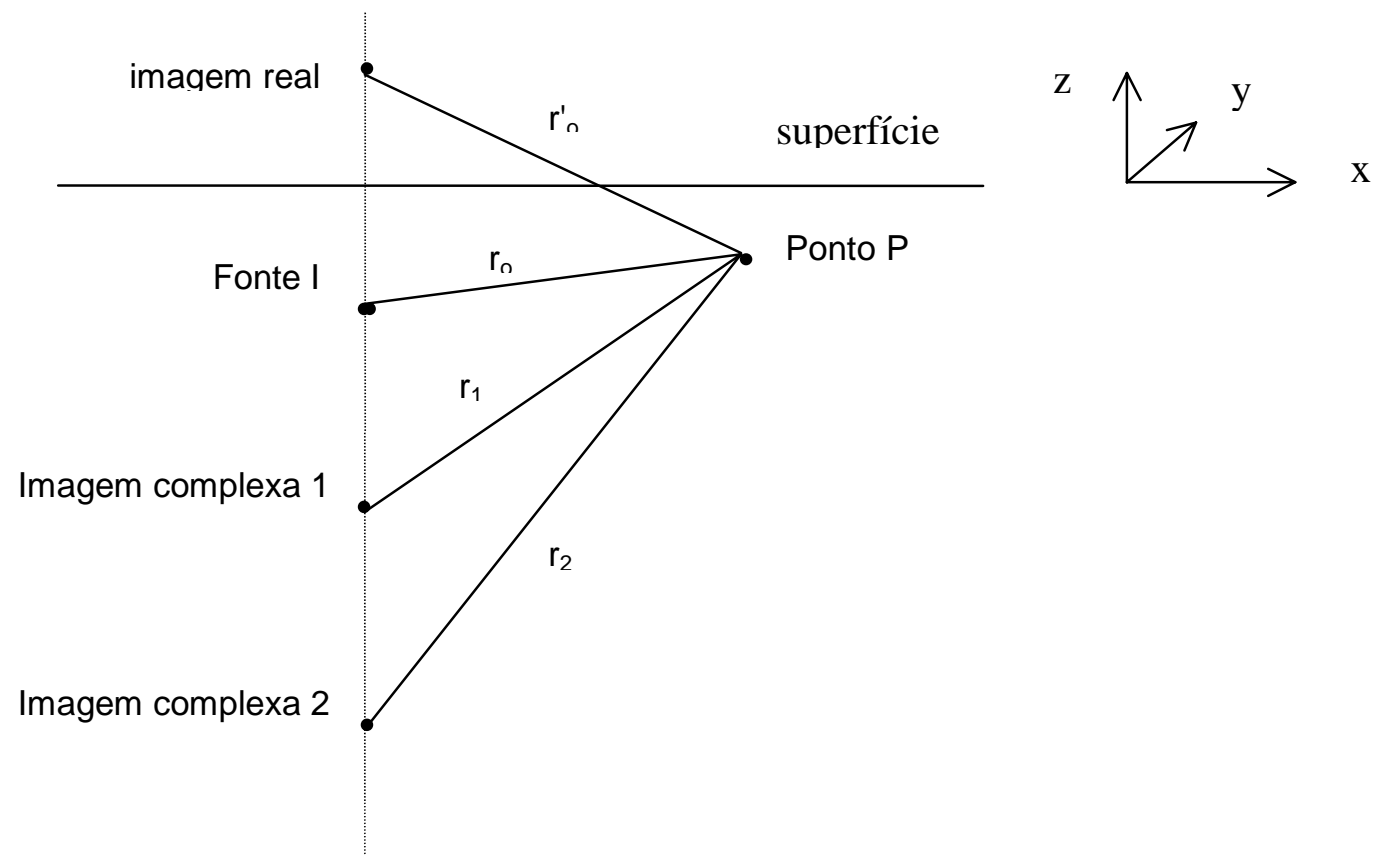

Figura 6 - Imagens complexas de fonte pontual 
Como G é real os ai's e bi's devem ser reais ou em pares conjugados. A parte real dos $\mathrm{b}_{\mathrm{i}}$ 's deve ser negativa para atender à condição do potencial nulo quando z tende a infinito.

b) Profundidades z e z' variáveis

Neste caso a função $S_{\exp }$ não é expandida:

$\frac{R(\gamma)}{1+R(\gamma) e^{-\gamma h_{1}}}=\sum_{i=1}^{N} a_{i} e^{\gamma b_{i}}$

Substituindo (46) em (643 e executando a transformação inversa teremos

$G=\frac{\rho I}{4 \pi}\left[\frac{1}{r_{0}}+\frac{1}{r_{0}^{\prime}}+\sum_{i=1}^{N} a_{i}\left(\frac{1}{r_{i 1}}+\frac{1}{r_{i 2}}+\frac{1}{r_{i 3}}+\frac{1}{r_{i 4}}\right)\right] \quad$, com:

$$
\begin{aligned}
& r_{i 1}=\sqrt{\left(x-x^{\prime}\right)^{2}+\left(y-y^{\prime}\right)^{2}+\left[z-\left(z^{\prime}-2 h_{1}+b_{i}\right)\right]^{2}} \\
& r_{i 2}=\sqrt{\left(x-x^{\prime}\right)^{2}+\left(y-y^{\prime}\right)^{2}+\left[z+\left(z^{\prime}+2 h_{1}-b_{i}\right)\right]^{2}} \\
& r_{i 3}=\sqrt{\left(x-x^{\prime}\right)^{2}+\left(y-y^{\prime}\right)^{2}+\left[z+\left(z^{\prime}-2 h_{1}+b_{i}\right)\right]^{2}} \\
& r_{i 4}=\sqrt{\left(x-x^{\prime}\right)^{2}+\left(y-y^{\prime}\right)^{2}+\left[z-\left(z^{\prime}+2 h_{1}-b_{i}\right)\right]^{2}}
\end{aligned}
$$


Esta fórmula corresponde exatamente à fórmula do potencial de uma fonte pontual em solo de duas camadas apresentada em [9], exceto pela presença das imagens complexas e por apresentar uma quantidade finita de imagens, não sendo necessário efetuar somatórias infinitas.

Os ai's e bi's são calculados por métodos de extração de pólos e resíduos, como o método de Prony em [29] ou métodos baseados em autovalores em [33].

\subsection{Generalização da Técnica de Imagens Complexas}

Para que possamos superar a limitação de eletrodos na primeira camada de Chow [29] e a de solos de duas camadas de Liu [33] devemos analisar mais detidamente os fundamentos da técnica de imagens complexas.

O princípio básico da técnica é aplicar uma separação de variáveis sobre a função kernel $F\left(z, z^{\prime}\right)$ e em seguida expandi-la em uma somatória de exponenciais:

$$
F\left(z, z^{\prime}\right)=u(\text { solo }) \cdot e^{f\left(z, z^{\prime}\right)}
$$

$\mathrm{u}\left(\right.$ solo) é função somente dos parâmetros do solo e $\mathrm{f}\left(\mathrm{z}, \mathrm{z}^{\prime}\right)$ somente da profundidade da fonte e do objeto. Fazendo a expansão em u(solo):

$$
F\left(\lambda, z, z^{\prime}\right)=e^{-\lambda \cdot f\left(z, z^{\prime}\right)} \cdot \sum_{j=1}^{N} a_{j} \cdot e^{\lambda \cdot b_{j}}
$$

A integral será então: 


$$
\begin{aligned}
& \int_{0}^{\infty} J_{0}\left(\lambda \cdot r_{x y}\right) \cdot F\left(\lambda, z, z^{\prime}\right) d \lambda=\operatorname{Itg}\left(z, z^{\prime}\right)=\int^{\infty} J_{0}\left(\lambda \cdot r_{x y}\right) \cdot e^{-\lambda \cdot f\left(z, z^{\prime}\right)} \cdot \sum_{j=1}^{N} a_{j} \cdot e^{\lambda \cdot b_{j}} \cdot d \lambda \therefore \\
& \operatorname{Itg}\left(z, z^{\prime}\right)=\int^{\infty} J_{0}\left(\lambda \cdot r_{x y}\right) \cdot \sum_{j=1}^{N} a_{j} \cdot e^{-\lambda \cdot\left(f\left(z, z^{\prime}\right)-b_{j}\right)} \cdot d \lambda \\
& \operatorname{Itg}\left(z, z^{\prime}\right)=\sum_{j=1}^{N} a_{j} \cdot \frac{1}{\sqrt{r_{x y}^{2}+\left(f\left(z, z^{\prime}\right)-b_{j}\right)^{2}}}
\end{aligned}
$$

A integral da função kernel será então substituída por uma somatória finita, onde os coeficientes $b_{j}$ e $a_{j}$ representam os pólos e os resíduos da resposta do solo a uma fonte pontual de corrente. A solução do potencial será dada por:

$$
V_{i}\left(r_{x y}, z, z^{\prime}\right)=\frac{I \rho_{i}}{4 \pi} \cdot\left(\frac{1}{\sqrt{r_{x y}^{2}+\left(z-z^{\prime}\right)^{2}}}+\frac{1}{\sqrt{r_{x y}^{2}+\left(z+z^{\prime}\right)^{2}}}+\sum_{j=1}^{N} a_{j} \cdot \frac{1}{\sqrt{r_{x y}^{2}+\left(f\left(z, z^{\prime}\right)-b_{j}\right)^{2}}}\right)
$$

Será necessário a determinação da função $f\left(z, z^{\prime}\right)$ e dos coeficientes das imagens complexas para que possamos explicitar a função potencial. O primeiro passo a ser dado é a separação de variáveis.

\subsection{Separação de variáveis}

Efetuaremos a separação de variáveis nas fórmulas (32) e (37) do capítulo 4 para z e z' como variáveis independentes. 


\subsubsection{Fonte e objeto na mesma camada.}

A fórmula (32) pode ser posta na forma:

$$
\begin{aligned}
F_{m m}\left(z, z^{\prime}\right)=e^{-\lambda\left|z-z^{\prime}\right|}+e^{\lambda\left(z+z^{\prime}\right)}+ & \left\lfloor\left(e^{-\lambda\left|z-z^{\prime}\right|}+e^{\lambda\left|z-z^{\prime}\right|}\right) e^{-2 \lambda h_{m}} \cdot K_{-m} K_{+m}+\right. \\
& +e^{\lambda\left(z+z^{\prime}\right)} \cdot e^{2 \lambda H_{m-1}} \cdot\left(K_{-m} \cdot K_{+m} \cdot e^{-2 \lambda H_{m}}+K_{-m}-e^{-2 \lambda H_{m-1}}\right)_{+} \\
& \left.+e^{-\lambda\left(z+z^{\prime}\right)} \cdot e^{-2 \lambda H_{m}} \cdot K_{+m}\right\rfloor M_{m}
\end{aligned}
$$

Observar que quando o solo é uniforme o termo entre colchetes de (51) é nulo, revelando que este é o termo que deve ser expandido na somatória. Veremos alguns casos particulares.

a) Fonte situada na primeira camada em solo com 3 ou mais camadas

Neste caso teremos $\mathrm{m}=2, \mathrm{~K}_{-\mathrm{m}}=1, \mathrm{H}_{\mathrm{m}-1}=0, \mathrm{H}_{\mathrm{m}}=\mathrm{h}_{1}$, obtendo:

$$
F_{11}\left(z, z^{\prime}\right)=e^{-\lambda\left|z-z^{\prime}\right|}+e^{\lambda\left(z+z^{\prime}\right)}+\frac{K_{1,2} e^{-2 \lambda h_{1}}}{1-K_{1,2} e^{-2 \lambda h_{1}}}\left(e^{-\lambda\left|z-z^{\prime}\right|}+e^{\lambda\left|z-z^{\prime}\right|}+e^{-\lambda\left(z+z^{\prime}\right)}+e^{\lambda\left(z+z^{\prime}\right)}\right)
$$

Esta é a formulação de Chow [29].

b) Fonte situada na última camada em solo com 3 ou mais camadas

Neste caso teremos $\mathrm{m}=\mathrm{N}+1, \mathrm{~K}_{+\mathrm{m}}=0, \mathrm{H}_{\mathrm{m}-1}=\mathrm{H}_{\mathrm{N}}$, obtendo:

$$
F_{m m}\left(z, z^{\prime}\right)=e^{-\lambda\left|z-z^{\prime}\right|}+e^{\lambda\left(z+z^{\prime}\right)}+e^{\lambda\left(z+z^{\prime}\right)} \cdot e^{2 \lambda H_{N}} \cdot\left(K_{-m}-e^{-2 \lambda H_{N}}\right)
$$

Neste caso podemos também realizar a expansão da forma proposta por Chow dado que há apenas 01 termo para $\mathrm{u}($ solo). 
c) Para os casos em que a fonte e o objeto ocupam camadas intermediárias entre a primeira e a última camada de um solo de mais de duas camadas, não é possível efetuar a separação de variáveis na forma proposta por Chow [29] com apenas um conjunto de imagens, sendo este o motivo da restrição dos eletrodos na primeira camada ou solos com duas camadas. Para levantar esta restrição deve-se considerar cada linha do termo entre colchetes da fórmula (51) como uma expansão independente, obtendo assim 3 conjuntos de imagens para representar o potencial dentro desta camada:

$$
\begin{aligned}
& F_{1 m m}\left(z, z^{\prime}\right)=\left(e^{-\lambda\left|z-z^{\prime}\right|}+e^{\lambda\left|z-z^{\prime}\right|}\right) e^{-2 \lambda h_{m}} \cdot K_{-m} K_{+m} \\
& F_{2 m m}\left(z, z^{\prime}\right)=e^{\lambda\left(z+z^{\prime}\right)} \cdot e^{2 \lambda H_{m-1}} \cdot\left(K_{-m} \cdot K_{+m} \cdot e^{-2 \lambda H_{m}}+K_{-m}-e^{-2 \lambda H_{m-1}}\right) M_{m} \\
& F_{3 m m}\left(z, z^{\prime}\right)=e^{-\lambda\left(z+z^{\prime}\right)} \cdot e^{-2 \lambda H_{m}} \cdot K_{+m} \cdot M_{m}
\end{aligned}
$$


Após a expansão a função potencial será então:

$$
\begin{aligned}
V_{m}\left(r_{x y}, z, z^{\prime}\right)=\frac{I \rho_{m}}{4 \pi} & \cdot\left[\frac{1}{\sqrt{r_{x y}^{2}+\left(z-z^{\prime}\right)^{2}}}+\frac{1}{\sqrt{r_{x y}^{2}+\left(z+z^{\prime}\right)^{2}}}+\right. \\
& \sum_{j=1}^{N_{1}} a_{1 j} \cdot\left(\frac{1}{\sqrt{r_{x y}^{2}+\left(\left|z-z^{\prime}\right|+2 \cdot h_{m}-b_{1 j}\right)^{2}}}+\frac{1}{\sqrt{r_{x y}^{2}+\left(\left|z-z^{\prime}\right|-2 \cdot h_{m}+b_{1 j}\right)^{2}}}\right)+ \\
& \sum_{j=1}^{N_{2}} a_{2 j} \cdot\left(\frac{1}{\sqrt{r_{x y}^{2}+\left(z+z^{\prime}+2 \cdot H_{m-1}+b_{2 j}\right)^{2}}}\right)+ \\
& \left.\sum_{j=1}^{N_{3}} a_{3 j} \cdot\left(\frac{1}{\sqrt{r_{x y}^{2}+\left(z+z^{\prime}+2 \cdot H_{m}-b_{3 j}\right)^{2}}}\right)\right]
\end{aligned}
$$

\subsubsection{Fonte e o objeto em camadas diferentes.}

Faremos a expansão somente para a fonte abaixo do objeto, $\mathrm{m}>\mathrm{n}$; para a outra condição podemos usar a simetria da função kernel:

Definindo $T_{m, n}^{\prime}=\prod_{\mathrm{j}=\mathrm{n}}^{\mathrm{m}-1} \frac{\mathrm{S}_{\mathrm{j}+1, \mathrm{j}}}{\mathrm{t}_{\mathrm{j}+1, \mathrm{j}}}$ e $\tau_{m, n}=\prod_{\mathrm{j}=\mathrm{n}}^{\mathrm{m}-1} \mathrm{t}_{\mathrm{j}+1, \mathrm{j}}$ teremos: 


$$
\begin{aligned}
F_{m>n}\left(z, z^{\prime}\right)= & \left(e^{-\lambda\left(z-z^{\prime}\right)}+e^{\lambda\left(z+z^{\prime}+2 \cdot H_{n-1}\right)}\right) \cdot \tau_{m, n}+ \\
& {\left[e^{-\lambda\left(z-z^{\prime}\right)} \cdot\left(1-\frac{1}{T^{\prime}{ }_{m, n} \cdot M_{m}}\right)+\right.} \\
& +e^{\lambda\left(z+z^{\prime}+2 \cdot H_{n-1}\right)} \cdot\left(K_{-n}-\frac{1}{T^{\prime}{ }_{m, n} \cdot M_{m}}\right)+ \\
& +e^{-\lambda\left(z+z^{\prime}+2 \cdot H_{m}\right)} \cdot K_{+m}+ \\
& \left.+e^{\lambda\left(z-z^{\prime}+2 \cdot H_{n-1}-2 \cdot H_{m}\right)} \cdot K_{-n} \cdot K_{+m}\right] \cdot T_{m n}^{\prime} \cdot M_{m} \cdot \tau_{m n}
\end{aligned}
$$

Para o caso geral serão necessários 4 conjuntos de imagens para representar o potencial gerado em camada diferente daquela da fonte:

$$
\begin{aligned}
V_{m n}\left(r_{x y}, z, z^{\prime}\right)=\frac{I \rho_{m}}{4 \pi} & . \tau_{m, n} \cdot\left\{\frac{1}{\sqrt{r_{x y}^{2}+\left(z-z^{\prime}\right)^{2}}}+\frac{1}{\sqrt{r_{x y}^{2}+\left(z+z^{\prime}+2 \cdot H_{n-1}\right)^{2}}}+\right. \\
+ & {\left[\sum _ { j = 1 } ^ { N _ { 1 } } a _ { 1 j } \cdot \left(\frac{1}{\sqrt{r_{x y}^{2}+\left(z-z^{\prime}-b_{1 j}\right)^{2}}+}\right.\right.} \\
& +\sum_{j=1}^{N_{2}} a_{2 j} \cdot\left(\frac{1}{\left.\sqrt{r_{x y}^{2}+\left(z+z^{\prime}+2 \cdot H_{n-1}+b_{2 j}\right)^{2}}\right)+}\right. \\
& +\sum_{j=1}^{N_{3}} a_{3 j} \cdot\left(\frac{1}{\left.\sqrt{r_{x y}^{2}+\left(z+z^{\prime}+2 \cdot H_{m}-b_{3 j}\right)^{2}}\right)+}\right. \\
& \left.\left.+\sum_{j=1}^{N_{4}} a_{4 j} \cdot\left(\frac{1}{\sqrt{r_{x y}^{2}+\left(z-z^{\prime}+2 \cdot H_{n-1}-2 \cdot H_{m}+b_{4 j}\right)^{2}}}\right)\right] T_{m, n}^{\prime} \cdot M_{m}\right\}
\end{aligned}
$$


Pode-se observar na fórmulas (51) e (58) que quando $K_{+m} / K_{+n}$ for nulo ou $K_{-n} / K_{-m}$ for unitário serão necessários apenas 02 conjuntos de imagens, que correspondem a fonte ou objeto na primeira ou última camada. Caso a condição seja simultânea então será necessário apenas um conjunto de imagens.

A Tabela 1 mostra o número de conjuntos de imagens necessários em função da posição relativa da fonte e objeto:

\begin{tabular}{|c|c|c|c|c|c|}
\hline fonte / objeto & 1 & 2 & --- & $\mathrm{N}-1$ & $\mathrm{~N}$ \\
\hline 1 & 1 & 2 & 2 & 2 & 1 \\
\hline 2 & 2 & 3 & 4 & 4 & 2 \\
\hline--- & 2 & 4 & 3 & 4 & 2 \\
\hline $\mathrm{N}-1$ & 2 & 4 & 4 & 3 & 2 \\
\hline N & 1 & 2 & 2 & 2 & 1 \\
\hline
\end{tabular}

\subsection{Determinação dos Pólos e Resíduos das Imagens}

O item 5.4.1 apresenta o Método de Prony clássico usado por Chow et all [29] para a determinação dos pólos e resíduos das imagens. Devido a limitações importantes deste 
método, será apresentada no item 5.4.2 uma adaptação do Método de Prony com o uso de autovalores e autovetores para superar estas limitações.

\subsubsection{Método de Prony como apresentado por Chow et all}

Se a função $\mathrm{f}(\mathrm{x})$ pode ser expandida em uma somatória de exponenciais do tipo:

$$
f(x) \cong A_{0} \cdot e^{\alpha_{0} \cdot x}+A_{1} \cdot e^{\alpha_{1} \cdot x}+\ldots+A_{N-1} \cdot e^{\alpha_{N-1} \cdot x}
$$

então, se $f(x)$ for amostrada em pontos igualmente espaçados $x j=j . \Delta x$ cada uma das exponenciais:

$e^{\alpha_{i} \cdot j}=\left(e^{\alpha_{i}}\right)^{j} \equiv \rho_{i}^{j}, i=0,1, \ldots, N-1$

satisfaz uma equação linear de diferenças de ordem $\mathrm{N}$ com coeficientes constantes:

$\mathrm{y}(\mathrm{j}+\mathrm{N})+\mathrm{C}_{\mathrm{N}-1} \cdot \mathrm{y}(\mathrm{j}+\mathrm{N}-1)+\mathrm{C}_{\mathrm{N}-2} \cdot \mathrm{y}(\mathrm{j}+\mathrm{N}-2)+\ldots+\mathrm{C}_{0} \cdot \mathrm{y}(\mathrm{j})=0$

A equação característica deste sistema é um polinômio de grau $\mathrm{N}$ :

$$
\rho^{N}+C_{N-1} \cdot \rho^{N-1}+C_{N-2} \cdot \rho^{N-2}+\ldots+C_{0}=0
$$


Como cada termo individual satisfaz a equação de diferenças homogênea, então qualquer combinação linear dos termos também satisfará a equação, em particular a função expandida original:

$f(j+N)+C_{N-1} \cdot f(j+N-1)+C_{N-2} \cdot f(j+N-2)+\ldots+C_{0} \cdot y(j)=0$

Serão então necessárias $2 \mathrm{~N}$ amostras para determinação unívoca das $2 \mathrm{~N}$ incógnitas da equação (60).

Sendo $f_{1}, f_{2} \ldots f_{2 N}$ os pontos amostrados da função $f$ deveremos executar os seguintes passos:

a) Encontrar os coeficientes do polinômio característico resolvendo o sistema linear:

$$
\sum_{j=0}^{N-1} C_{j} \cdot f_{j+k}=-f_{N+k}, \mathrm{k}=1,2, \ldots \mathrm{N}
$$

Os coeficientes $C_{j}$ são todos reais pois os f's são reais.

b) Obter as $\mathrm{N}$ raízes do polinômio:

$$
\rho^{N}+C_{N-1} \cdot \rho^{N-1}+C_{N-2} \cdot \rho^{N-2}+\ldots+C_{0}=0
$$

As raízes $\rho_{\mathrm{j}}$ podem ser reais ou complexas em pares conjugados.

c) Determinar os pólos do sistema:

$$
\alpha_{j}=\frac{\operatorname{Ln}\left(\rho_{j}\right)}{\Delta x}
$$


d) Com os valores obtidos em (62) montar outro sistema linear de ordem $\mathrm{N}$ a partir da fórmula (60) e dos primeiros $\mathrm{N}$ valores amostrados:

$\sum_{j=1}^{N} A_{j} \cdot e^{\alpha_{j} \cdot x}=f_{j}$

Os valores $A_{j}$ são os resíduos associados aos pólos $\alpha_{j}$ e podem ser reais ou em pares conjugados.

Uma das limitações deste método é que o número de ordem $\mathrm{N}$ não é conhecido a priori, de forma que a estimativa feita pode provocar erros significativos sem que haja uma forma de quantificá-los.

Outra limitação importante é que como o número de amostras é o dobro da ordem do sistema, se for necessário aumentar a taxa de amostragem para acompanhar variações rápidas da função a ordem do sistema crescerá proporcionalmente, aumentando desnecessariamente os requisitos de memória e de tempo de processamento.

Para contornar estas dificuldades foi utilizada uma adaptação do método de Prony proposto por Blaricum e Mittra [39], resolvendo o sistema linear inicial do passo a) usando o método da decomposição em autovalores e autovetores.

\subsubsection{Método de Prony com solução por autovalores}

A diferença neste caso é que o sistema linear inicial é amostrado com um número maior que o dobro da ordem esperada do sistema resultando em um sistema com mais equações do que incógnitas. 
O valor da taxa de amostragem é fixada em função da maior espessura de camada existente no modelo, e o ponto final da amostragem em função do menor valor de espessura de camada existente, sem dependência da ordem do sistema, observando-se sempre que o número de amostras deve ser maior do que o de incógnitas.

Estima-se um valor inicial $\mathrm{N}_{0}$ para a ordem do sistema e decompõe-se a matriz retangular, obtendo-se os autovalores e os autovetores. O algoritmo de decomposição utilizado foi o de Press et all [38].

Se algum autovalor for nulo ou, em casos práticos, for menor que o limite especificado $\left(10^{-6}\right.$ a $\left.10^{-8}\right)$, a ordem do sistema é reduzida pela quantidade de autovalores nulos e o sistema é recalculado. Se não existirem autovalores nulos então a ordem do sistema é aumentada de 1 e os autovalores são determinados novamente. Este processo é repetido até que se encontre pelo menos um autovalor nulo.

Uma vez definida a ordem do sistema pode-se continuar no passo b) de 5.2.1 para determinar os pólos e resíduos. 


\section{ASPECTOS COMPUTACIONAIS}

A implementação da metodologia apresentada envolve alguns aspectos gerais de arquitetura de software e também problemas específicos de código. Serão feitas considerações sobre os aspectos principais da implementação.

O programa foi escrito com um compilador Borland Delphi 2.0, com linguagem Pascal orientada a objetos e ambiente visual para utilização em PC's com Windows 95 ou superior e Windows NT 4.0 ou superior .

Todas as matrizes e vetores são armazenadas em variáveis dinâmicas para otimizar o uso da memória.

O programa em sua versão final tem cerca de $1,5 \mathrm{Mb}$ e necessita de $12 \mathrm{Mb}$ de memória livre em sua capacidade máxima para evitar o uso do arquivo de troca do Windows.

\subsection{Entrada de Dados da Malha e do Solo}

Entrada das informações relativas aos eletrodos, com posição inicial e final, raio e tipo, se ativo ou passivo.

As camadas foram limitadas a 4, quantidade suficiente para permitir comparação com outros resultados da literatura. Não há limitações técnicas para a quantidade de camadas. 


\subsection{Discretização do domínio}

A discretização foi feita dividindo-se os eletrodos de tal maneira a preservar a hipótese de densidade de corrente constante, implicando em segmentar mais os trechos na periferia da malha e nos pontos de cruzamento no caso de cabos e sempre segmentando as hastes com o primeiro segmento da ordem da profundidade de cravação. Um sintoma típico de segmentação inadequada é a existência de potenciais na superfície maiores do que o potencial médio sobre os eletrodos.

Para preservar a hipótese de filamento de corrente o menor segmento foi mantido da ordem de 50 vezes o raio do condutor.

Devido à forma de solução genérica das equações de potencial em (11) e (14) foram introduzidas singularidades ao longo do eixo dos segmentos. Estas singularidades são resolvidas numericamente pelo deslocamento radial do ponto de cálculo por um valor igual ao raio do segmento.

\subsection{Determinação das imagens complexas}

As funções de Green são amostradas e as imagens são calculadas.

O intervalo da amostragem foi fixado em $1 / 20$ da menor espessura existente. O ponto final da amostragem foi estabelecido em 20 vezes o valor da maior espessura de camada. Esta condição implica no cálculo de pelo menos 400 pontos, mas garante 
que todos os componentes de freqüência relevantes serão considerados no cálculo das imagens. O programa pode calcular até 50.000 pontos.

O número de imagens inicial foi estimado como o número de camadas mais 2 . O valor mínimo dos autovalores foi fixado em $10^{-6}$.

Foram implementadas apenas as funções com fonte abaixo do objeto. O cálculo inverso utiliza a simetria das funções de Green.

Foi necessário implementar bibliotecas de rotinas complexas para o cálculo das imagens pois os pólos e resíduos podem ser complexos.

\subsection{Montagem da matriz de resistências mútuas}

As fórmula (9) e (14) são implementadas para calcular as resistências mútuas da matriz e o sistema linear de ordem $\mathrm{M}$ é resolvido.

A ordem $\mathrm{M}$ é igual ao produto do número de eletrodos pela segmentação média utilizada. Por exemplo, se tivermos 50 eletrodos com uma segmentação média de 10 teremos $\mathrm{M}=500$. Esta matriz é simétrica e cheia, portanto os requisitos de memória necessária para o armazenamento dos dados pode ser uma limitação importante para malhas muito grandes. O programa pode manipular até matrizes de ordem $1000 \mathrm{x}$ 1000, ocupando cerca de $8 \mathrm{Mb}$ de memória RAM. 
Devido à introdução dos eletrodos passivos a fatoração de Cholesky não pode ser utilizada porque a matriz deixou de ser positiva definida. Foi utilizado o algoritmo de decomposição LU de Press et all [38] para a solução do sistema linear.

\subsection{Cálculo dos potenciais e exploração dos resultados}

As fórmulas (8) e (14) são implementadas para o cálculo do potencial gerado pela malha.

A saída mais habitual é a de traçar perfis de potenciais ao longo de algumas linhas, por exemplo a diagonal da malha, e plotar os valores do potencial de toque, superfície e de passo.

O uso dos eletrodos passivos permite a determinação de potenciais de transferência para cercas ou eletrodutos e também os potenciais de toque na vizinhança destes eletrodos. 


\section{RESULTADOS OBTIDOS}

Para verificação da metodologia apresentada serão feitas comparações de resultados com trabalhos publicados.

\subsection{Exemplo de Chow et all [29]}

O eletrodo toroidal descrito em [29] e [30] será simulado para verificação dos resultados.

Este eletrodo é um toróide de $300 \mathrm{~m}$ de raio, seção transversal com raio de $30 \mathrm{~cm}$, profundidade de 2,75 m, injetando uma corrente de 2.000 A no solo. A hipótese de fonte linear de corrente é utilizada.

O solo foi estratificado em 4 camadas. A Tabela 2 mostra os valores de resistividades e espessuras:

\begin{tabular}{|c|c|c|c|c|}
\hline Camada & 1 & 2 & 3 & 4 \\
\hline Resistividade $(\Omega . \mathrm{m})$ & 200 & 230 & 110 & 20 \\
\hline Espessura (m) & 3 & 15 & 5 & $\infty$ \\
\hline \multicolumn{5}{|c|}{ Tabela 2 - Dados do Solo } \\
\hline
\end{tabular}

No caso de um toróide a simetria impõe que a densidade de corrente seja uniforme, não sendo necessária a resolução de um sistema matricial. 
A Figura 7 mostra a posição do toróide.

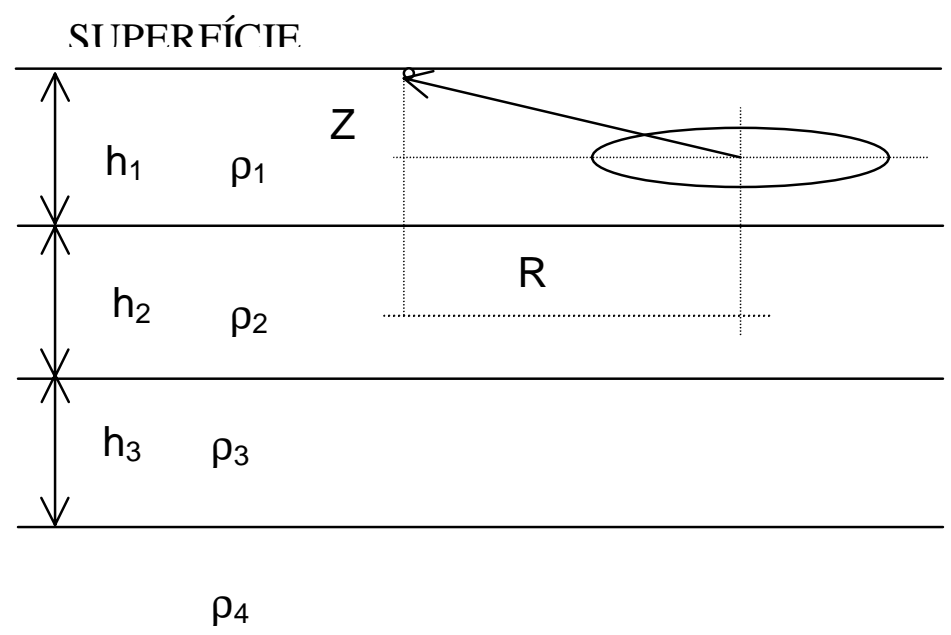

Figura 7- Toróide na primeira camada

\subsubsection{Modelo utilizado}

A função de Green derivada a partir da fórmula (51) para $\mathrm{N}=4$ é:

$F_{11}\left(z, z^{\prime}\right)=e^{-\lambda\left|z-z^{\prime}\right|}+e^{\lambda\left(z+z^{\prime}\right)}+\frac{K_{2,3} e^{-2 \lambda h_{1}}}{1-K_{2,3} e^{-2 \lambda h_{1}}}\left(e^{-\lambda\left|z-z^{\prime}\right|}+e^{\lambda\left|z-z^{\prime}\right|}+e^{-\lambda\left(z+z^{\prime}\right)}+e^{\lambda\left(z+z^{\prime}\right)}\right)(63)$

A expansão exponencial de (30) foi feita com o método de Prony usado por Chow [29], utilizando 8 amostras igualmente espaçadas entre $\lambda=0$ e $\lambda=1$ para determinação de 4 imagens. 
A Tabela 3 mostra os valores dos $a_{i}$ 's e $b_{i}$ 's para este caso:

\begin{tabular}{|c|c|c|c|c|}
\hline $\mathrm{i}$ & 1 & 2 & 3 & 4 \\
\hline $\mathrm{a}_{\mathrm{i}}$ & 0,069768 & 0,0049189 & $-0,26234+\mathrm{j} 0,15429$ & $-0,26234-\mathrm{j} 0,15429$ \\
\hline$b_{\mathrm{i}}(\mathrm{m})$ & 0 & $-6,01680$ & $-31,191+\mathrm{j} 3,8654$ & $-31,191-\mathrm{j} 3,8654$ \\
\hline \multicolumn{4}{|c|}{ Tabela 3 - Pólos e Resíduos } \\
\hline
\end{tabular}

Observar que quando há uma imagem complexa existe seu conjugado correspondente.

A Figura 8 mostra o gráfico dos valores analíticos de (30), os valores reconstruídos com a expansão de Chow [29], Tabela II e com os valores da Tabela 3.

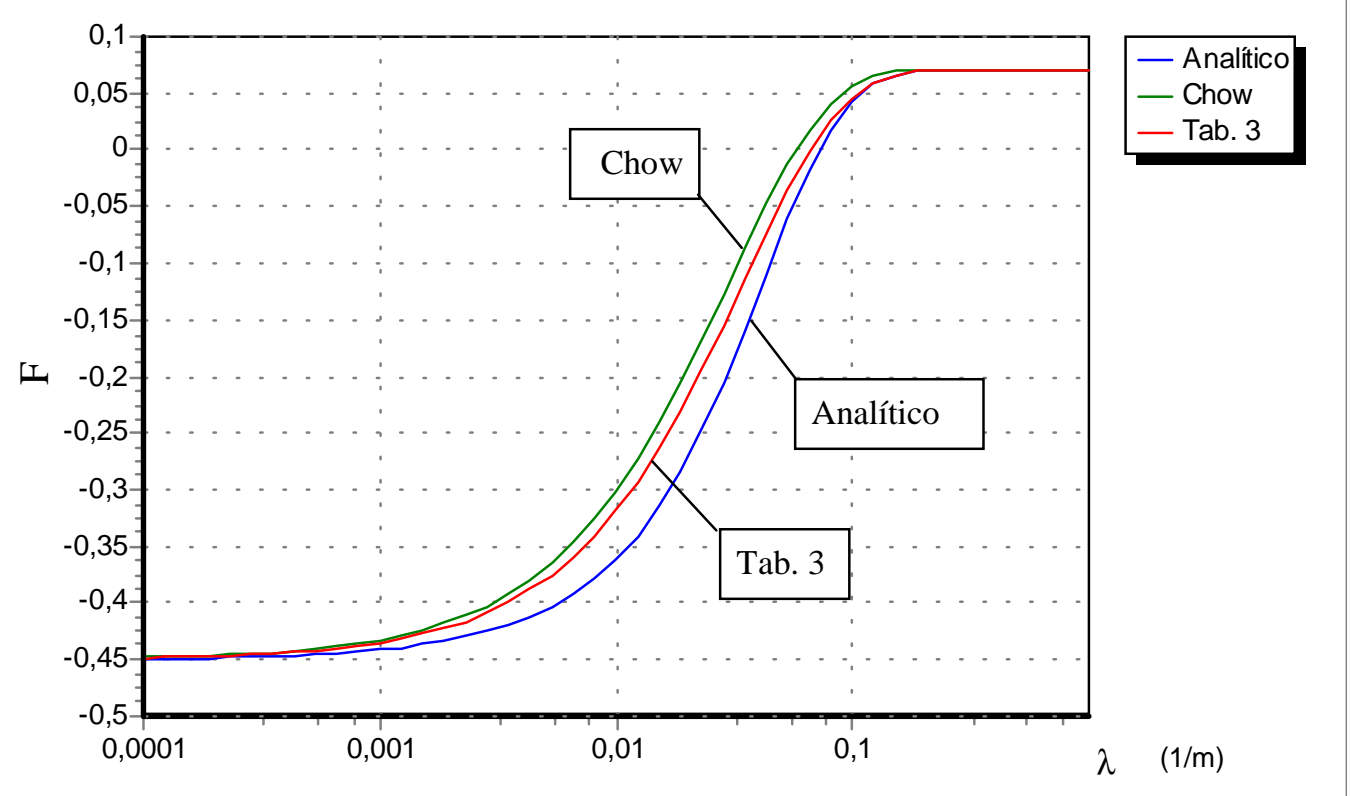

Figura 8- Valores reconstruídos 


\subsubsection{Cálculo do potencial na superfície}

O potencial na superfície $(\mathrm{z}=0)$ foi calculado para $\mathrm{R}$ entre $280 \mathrm{~m}$ e $315 \mathrm{~m}$ para comparação com a Fig. 4 de [28].

O cálculo foi realizado a partir da integração do potencial da fonte pontual da fórmula (10) sobre o anel situado no centro da seção transversal do toróide.

A Figura 9 mostra o potencial calculado com os dados da Tabela II de Chow [28], os valores retirados das curvas dadas em Legace [25] (marcados com cruz) e os calculados com os pólos e resíduos da Tabela 2.

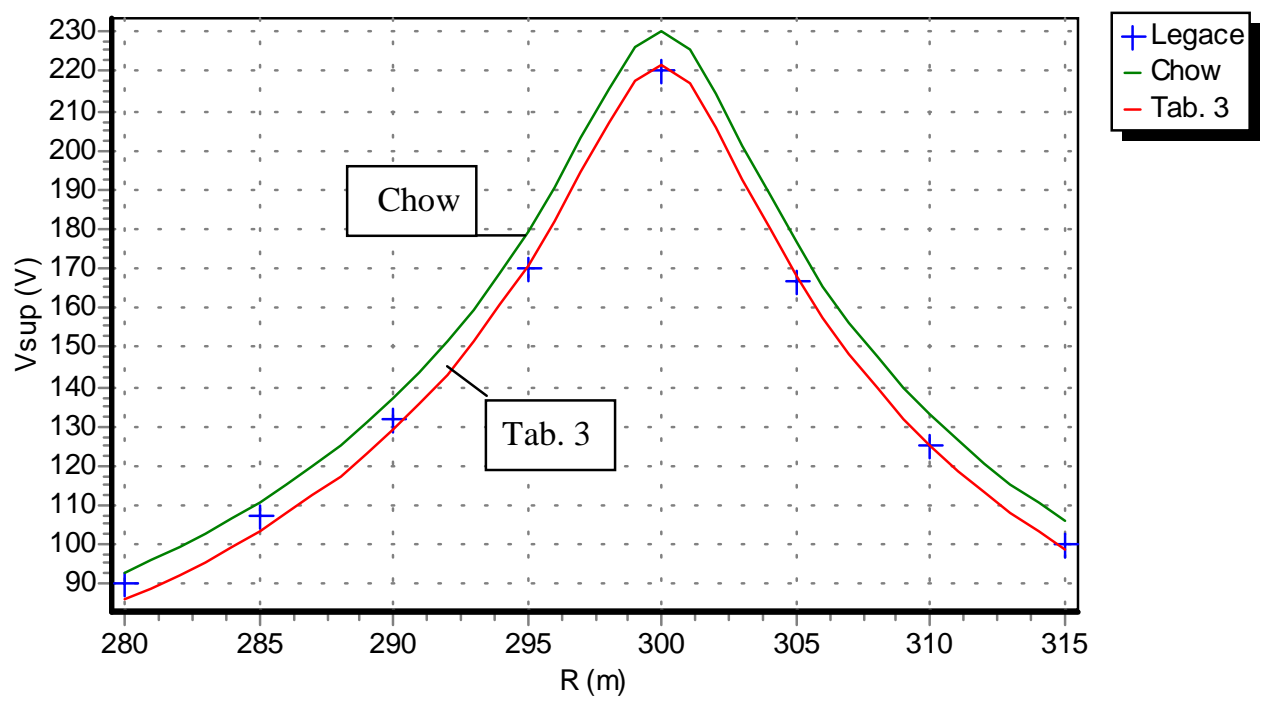

Figura 9- Potenciais na superfície do solo sobre o eletrodo. 
A Figura 10 mostra uma comparação com os resultados obtidos para valores de $\mathrm{R}$ entre 0 e $600 \mathrm{~m}:$

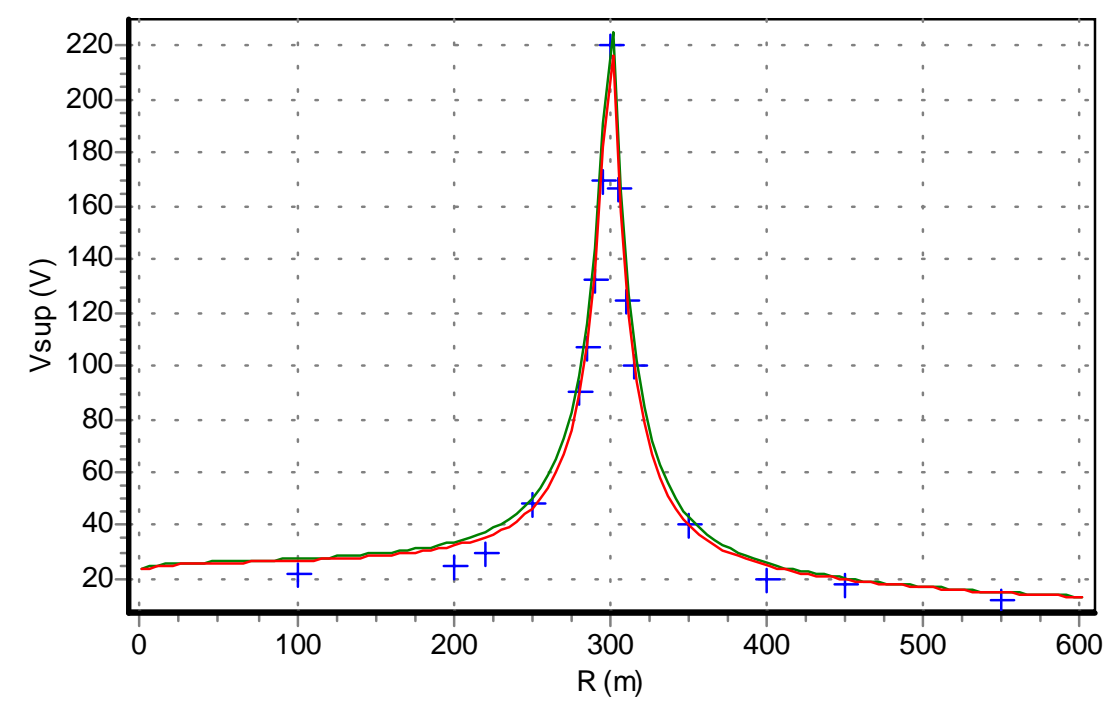

Figura 10 - Potenciais na superfície do solo sobre o eletrodo

Os gráficos mostrados nas Figuras 9 e 10 mostram boa reprodução dos potenciais quando comparados com [29] e [28], evidenciando que as imagens complexas podem ser efetivamente utilizadas nesta aplicação.

O cálculo de potenciais para eletrodos complexos apresentará a mesma seqüência que o caso do toróide, exceto que será necessário segmentar o eletrodo e resolver o sistema matricial. 


\subsubsection{Imagens para o solo de Kovarski}

A estrutura do solo citado em Kovarski at all [25] evidencia a limitação do método de Prony clássico utilizado por Chow et all [29].

A Tabela 4 mostra as 04 imagens usados por Chow e as 7 calculadas pelo AMAICom 4.

\begin{tabular}{|c|c|c|c|c|}
\hline \multirow{2}{*}{$\mathrm{N}$} & \multicolumn{2}{|c|}{ Chow } & \multicolumn{2}{c|}{ AMAICom } \\
\cline { 2 - 5 } & Resíduos & Pólos & Resíduos & Pólos \\
\hline 1 & $+1,1293$ & $-3680,23$ & $-0,33116$ & -1573395 \\
\hline 2 & $-0,4564$ & $-1995,46$ & $+1,33509$ & -1069959 \\
\hline 3 & $+0,6049$ & $-1000,0$ & $-2,95778$ & $-558694,6$ \\
\hline 4 & $-0,7778$ & 0,0 & $+1,72283$ & $-131326,3$ \\
\hline 5 & --- & --- & $+1,03496$ & $-35420,8$ \\
\hline 6 & --- & --- & $+0,47384$ & $-1106,67$ \\
\hline 7 & --- & --- & $-0,777778$ & 0,0 \\
\hline
\end{tabular}

A Figura 11 mostra a função kernel analítica, a aproximação de Chow e a do AMAICom. Observar que para valores pequenos de $\lambda(1 / \mathrm{m})$ entre $10^{-5}$ e $10^{-6}$, equivalentes a distâncias de $10^{5}$ e $10^{6} \mathrm{~m}$ do eletrodo, a expansão de Chow apresenta erros de mais de $100 \%$. Notar que a distância ao ponto com erro máximo é cerca de 10 vezes a profundidade da última camada. 
$\mathrm{F}(\lambda)$

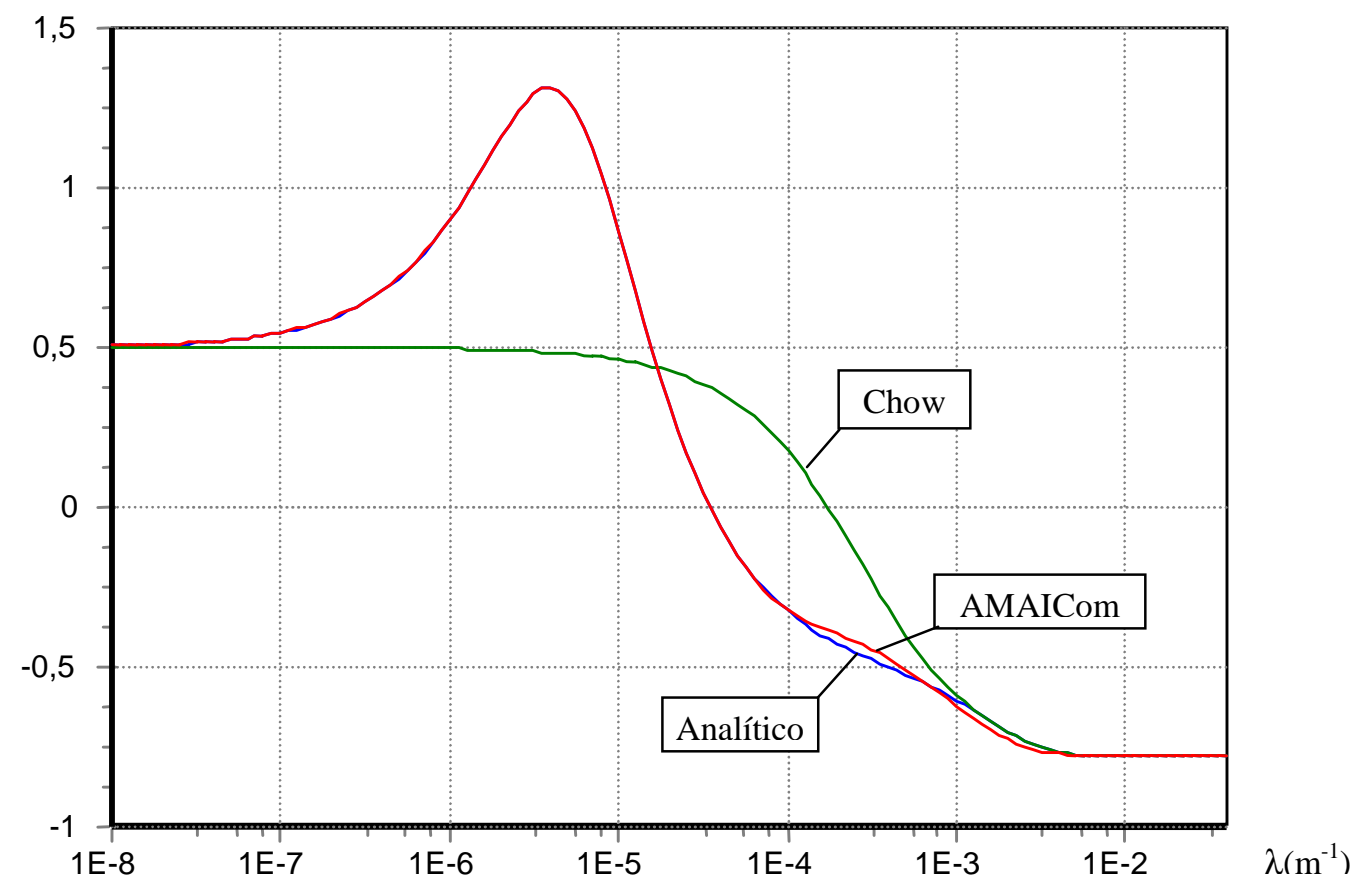

Figura 11 - Valores reconstruídos do kernel de Kovarski

Notar que para o cálculo das 7 imagens foram usadas 24000 amostras da função kernel contra apenas 08 amostras para as 4 imagens de Chow.

\subsection{Solo de 2 camadas - Exemplo de Li e Dawalibi}

Este eletrodo é estudado nos trabalhos de Li et all [33] e Dawalibi [17]; é constituído por uma malha quadrada com lado de 20 metros com 04 meshs e 9 hastes a uma profundidade de $0,5 \mathrm{~m}$. Cada haste tem $10 \mathrm{~m}$ de comprimento e $2 \mathrm{~cm}$ de diâmetro. Cada cabo tem diâmetro de $1 \mathrm{~cm}$.

A Figura 12 mostra a vista superior da malha. A linha na diagonal do primeiro mesh é o caminho onde foi calculado o potencial de toque. 
A resistividade da primeira camada foi fixada em $100 \Omega$.m e a espessura em 5 m. A resistividade da segunda camada foi fixada variando-se o fator de reflexão de $-0,9$ a $+0,9$.

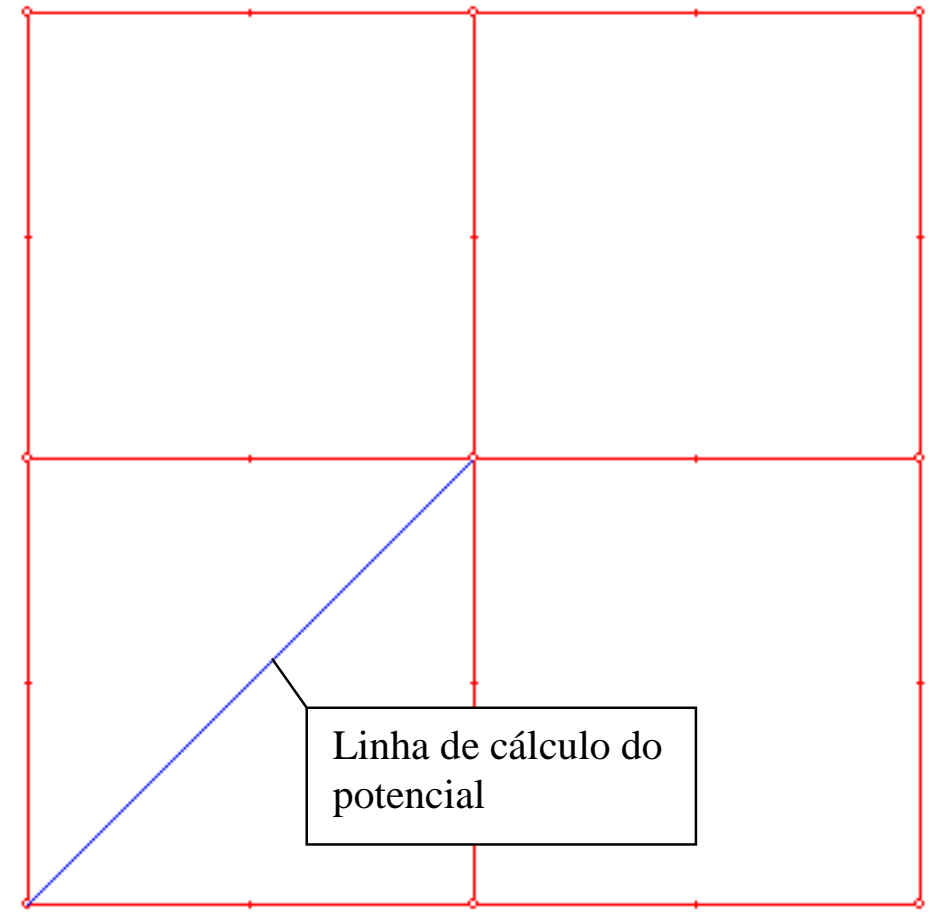

FIGURA 12 - VISTA SUPERIOR DA MALHA

A Tabela 5 mostra os valores da resistência de aterramento e o valor do potencial de toque máximo em percentagem em relação à elevação de potencial da malha.

A discretização utilizada foi a padrão com 3 subdivisões para os cabos e 7 para as hastes. 


\begin{tabular}{|c|c|c|c|c|c|c|}
\hline \multirow[b]{2}{*}{$\mathrm{k}$} & \multicolumn{3}{|c|}{ Resistência $(\Omega)$} & \multicolumn{3}{|c|}{ Vtoque (\%) } \\
\hline & $\mathrm{Li}$ & Dawalibi & AMAICom & $\mathrm{Li}$ & Dawalibi & AMAICom \\
\hline 0,9 & 7,70 & 7,78 & 8,02 & 6,51 & 6,60 & 7,04 \\
\hline 0,5 & 3,46 & 3,50 & 3,50 & 12,9 & 13,4 & 14,2 \\
\hline 0,0 & 1,79 & 1,81 & 1,78 & 20,8 & 21,0 & 21,7 \\
\hline$-0,5$ & 0,80 & --- & 0,787 & 27,0 & ---- & 29,7 \\
\hline$-0,9$ & 0,15 & 0,16 & 0,153 & 34,1 & 35,0 & 37,1 \\
\hline
\end{tabular}

Os resultados da resistência de aterramento e do potencial de toque mostram variações menores que $3 \%$ entre os três conjuntos de resultados.

Para uma verificação adicional destes resultados o Ground-3D foi utilizado com os valores extremos de $\mathrm{k}=0,9$ e $\mathrm{k}=-0,9$, obtendo-se respectivamente resistências de $7,38 \Omega$ e $0,12 \Omega$ e potenciais de toque de $6,3 \%$ e $37 \%$.

\subsection{Exemplo de Vujevic e Kurtovic}

Este eletrodo [34] é composto por hastes e cabos com $11 \mathrm{~mm}$ de diâmetro a uma profundidade de $0,5 \mathrm{~m}$ e cabos com $5 \mathrm{~mm}$ de diâmetro simulando uma cerca metálica. O solo apresenta uma estrutura de 03 camadas, com resistividades de 10, 100 e $500 \Omega . m$ respectivamente e espessuras de 2 e $10 \mathrm{~m}$. 
A Figura 13 mostra uma vista superior da malha. A linha na segunda metade da malha é o caminho de cálculo do potencial na superfície.

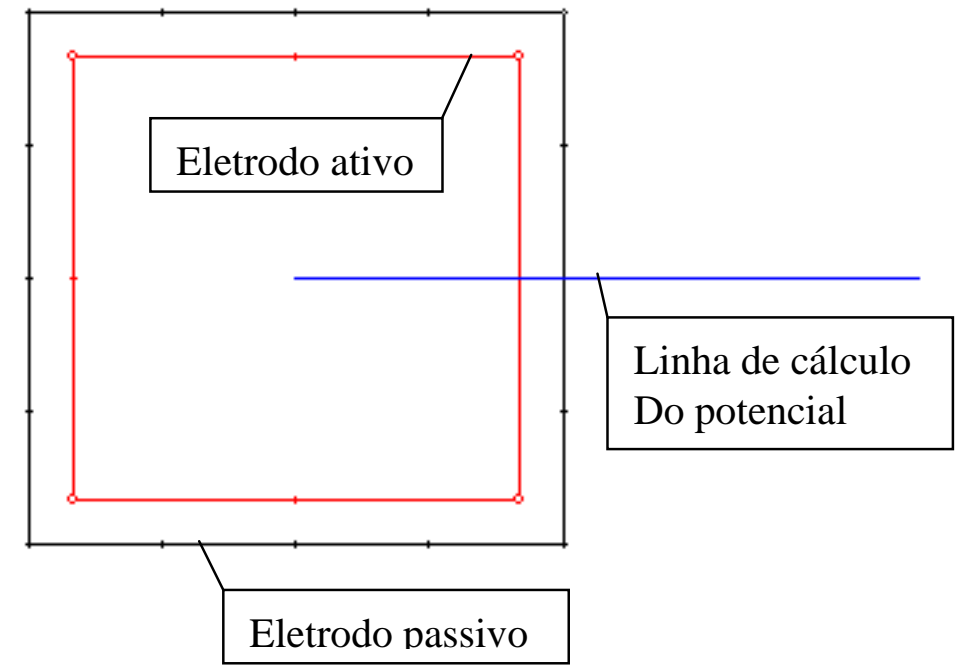

Figura 13 - Exemplo de Vujevic e Kurtovic

A Tabela 6 mostra valores da elevação de potencial dos eletrodos ativos e passivos e o valor do potencial em alguns pontos na superfície do solo, com referência 0 no centro da malha. A corrente injetada no eletrodo interno foi de $1000 \mathrm{~A}$. 


\begin{tabular}{|c|c|c|}
\hline Grandeza & Vujevic e Kurtovic & AMAICom \\
\hline $\begin{array}{c}\text { Elevação de potencial do } \\
\text { eletrodo ativo (V) }\end{array}$ & 1968 & 1972 \\
\hline $\begin{array}{c}\text { Elevação de potencial do } \\
\text { eletrodo passivo (V) }\end{array}$ & 1765 & 1838 \\
\hline Potencial $x=0$ & 1835 & 1822 \\
\hline Potencial $x=5$ & 1820 & 1772 \\
\hline Potencial $x=6$ & 1551 & 1206 \\
\hline Potencial $x=10$ & 1206 & \\
\hline \multicolumn{2}{|c|}{ Potencial $x=20$} & Tabela 6 - Comparação com 03 camadas \\
\hline
\end{tabular}

Os resultados mostram excelente concordância entre os dois métodos.

\subsection{IEEE-80 / 1986}

Serão estudados dois casos do Anexo C do IEEE-80 / 1986, o caso C4, com solo de duas camadas e espaçamento uniforme e o C6, com solo uniforme e espaçamento variável.

\subsubsection{Caso C-4 : 2 camadas com espaçamento uniforme}

Malha quadrada com lado de 60,96 m, 04 meshs, 09 hastes. Cabos com $10 \mathrm{~mm}$ de diâmetro e hastes com 0,5" de diâmetro e 9,144 m de comprimento. A profundidade da 
malha é de $0,5 \mathrm{~m}$; a resistividade da primeira e segunda camada é de $300 \Omega . \mathrm{m}$ e 100 $\Omega . m$ respectivamente e a espessura da primeira camada é de 4,572 $\mathrm{m}$.

A Figura 14 mostra uma vista superior da malha:

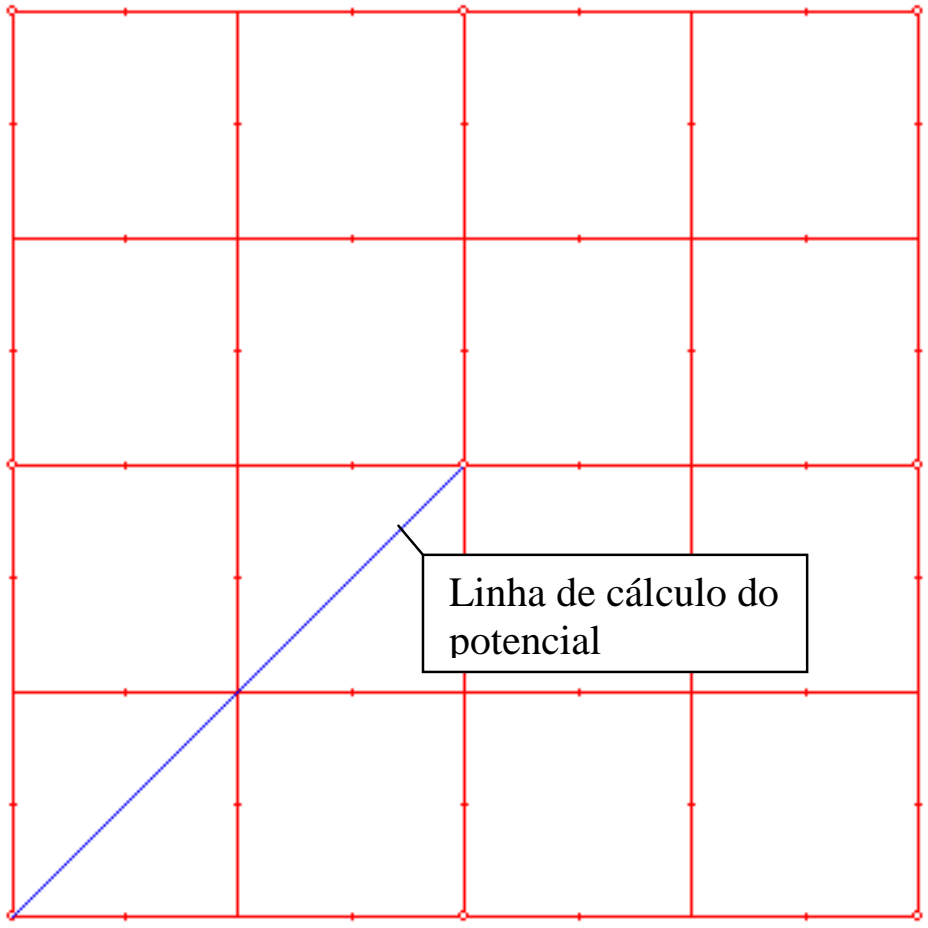

Figura 14 - Eletrodo Figura C4 IEEE-80 /1986

A Tabela 7 mostra os valores da resistência de aterramento e do potencial de toque do IEEE-80, de Haffner [36] e os obtidos com o AMAICom: 


\begin{tabular}{|c|c|c|}
\cline { 2 - 3 } \multicolumn{1}{c|}{} & Resistência $(\Omega)$ & Potencial de toque $(\%)$ \\
\hline IEEE-80 / 1986 & 1,353 & 49,66 \\
\hline Haffner et all [36] & 1,169 & 45,06 \\
\hline AMAICom & 1,141 & 44,04 \\
\hline \multicolumn{2}{|c|}{ Tabela 7 - Eletrodo C4 do IEEE-80 / 1986 } \\
\hline
\end{tabular}

A diferença percentual do potencial de toque máximo foi de $4,6 \%$ em relação ao IEEE-80 e de $1 \%$ em relação a Haffner.

A diferença percentual da resistência de aterramento foi de $16 \%$ em relação ao IEEE-80 e de $2,4 \%$ em relação a Haffner.

A Figura 15 mostra o potencial na superfície sobre o caminho mostrado na Figura 13.

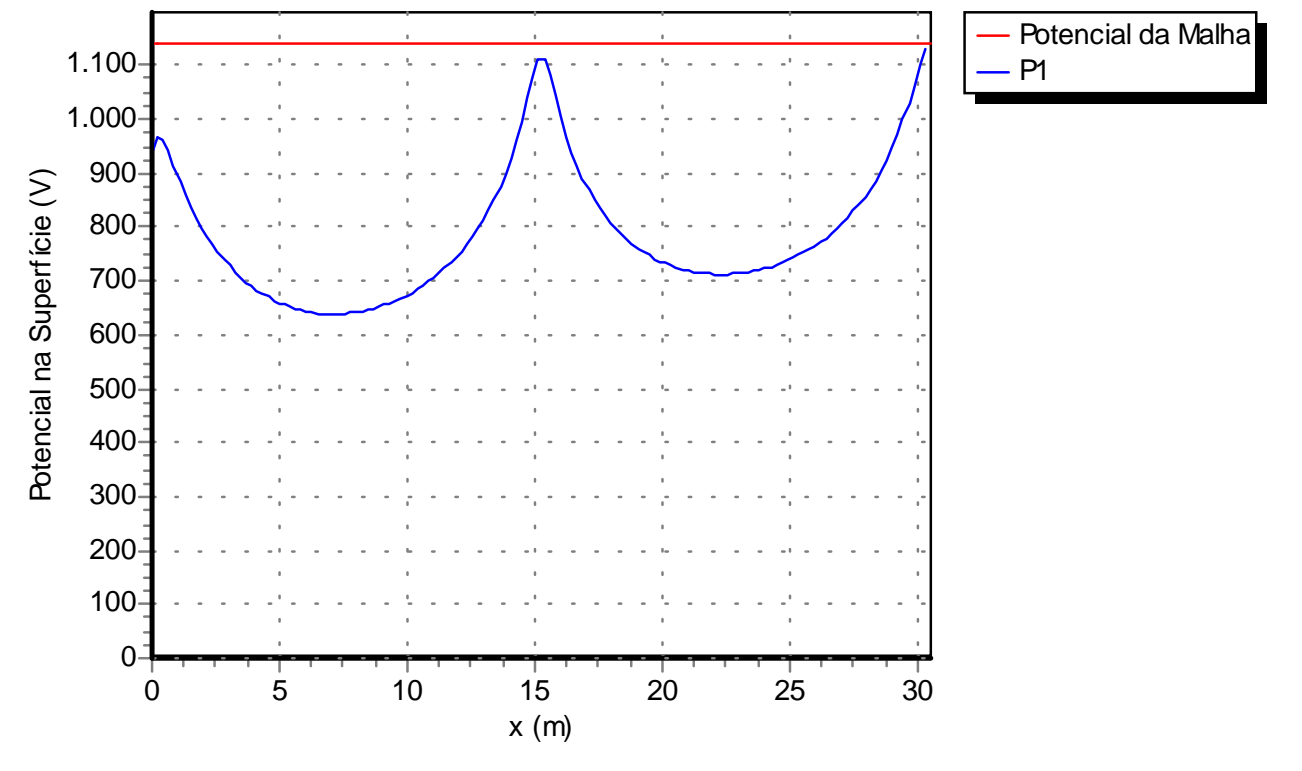

Figura 15 - Potencial na superfície do solo 


\subsubsection{Caso C-6 : Solo uniforme com espaçamento variável}

Malha quadrada com lado de 91,44 m, 08 meshs, 25 hastes. Cabos com $10 \mathrm{~mm}$ de diâmetro e hastes com 0,5 " e 9,144 m de comprimento. A profundidade da malha é de 0,5 m; a resistividade do solo é de $300 \Omega . \mathrm{m}$. O espaçamento dos meshs é variável. A Figura 16 mostra uma vista superior da malha:

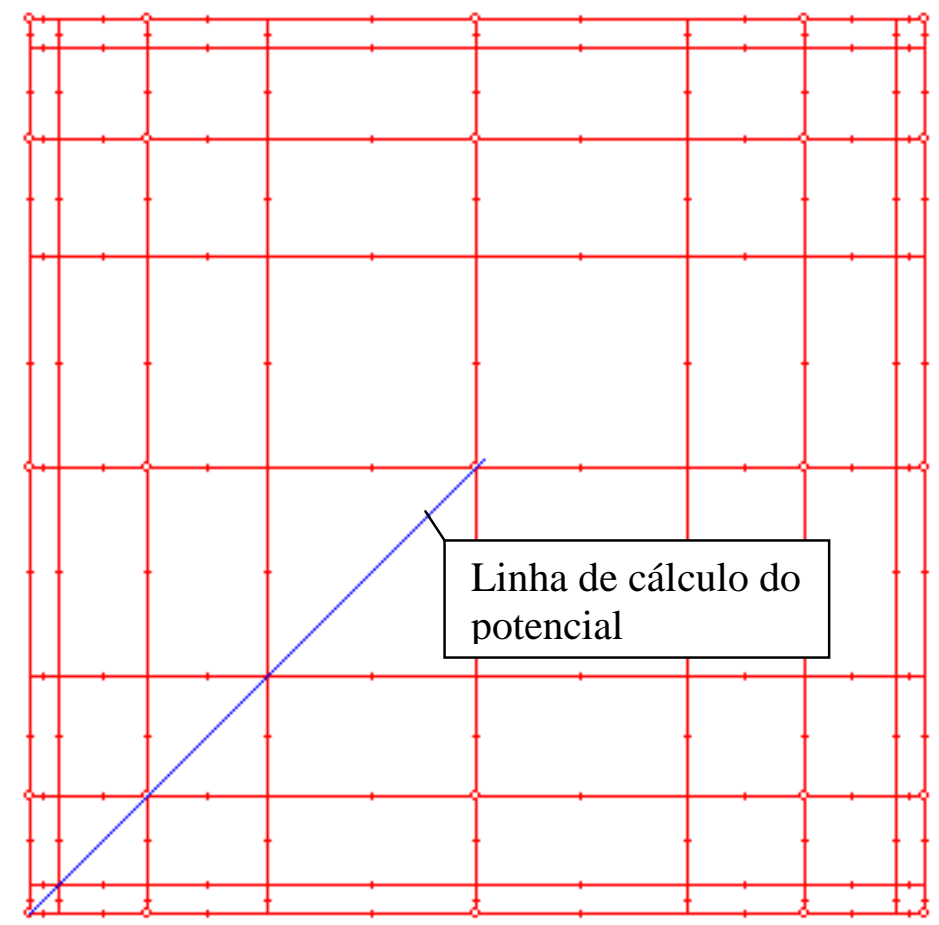

Figura 16 - Eletrodo Figura C4 IEEE-80 /1986

A Tabela 8 mostra os valores da resistência de aterramento e do potencial de toque do IEEE-80 e os valores obtidos com o AMAICom: 


\begin{tabular}{|c|c|c|}
\hline & Resistência $(\Omega)$ & Potencial de toque $(\%)$ \\
\hline IEEE-80 / 1986 - C6 & 1,416 & 17,08 \\
\hline AMAICom & 1,468 & 15,86 \\
\hline \multicolumn{2}{|c|}{ Tabela 8 - Eletrodo C6 do IEEE-80 / 1986 } \\
\hline
\end{tabular}

O potencial de toque máximo ocorreu no mesh central e não no mesh do canto.

A diferença percentual é de 3,6\% entre os valores de resistência e de 1,2\% para o potencial de toque.

A figura 17 mostra a curva de potencial na superfície do solo:

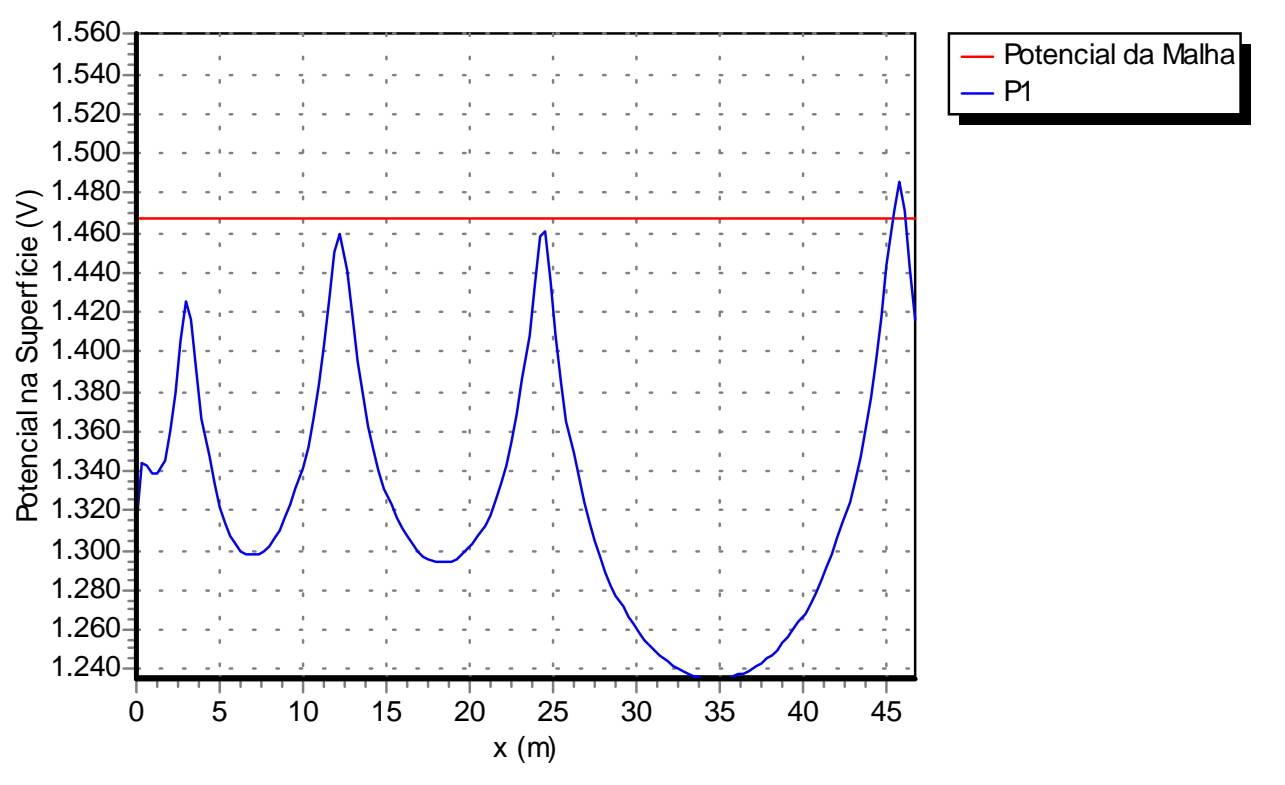

Figura 17 - Potencial na superfície do solo

Podemos observar que a segmentação utilizada produziu um valor de potencial na superfície do solo maior do que o potencial sobre os eletrodos, indicando que a segmentação está inadequada. No caso do IEEE-80, a Fig. C7 mostra potenciais acima 
do valor dos eletrodos já na passagem sobre o terceiro cabo $(\mathrm{x}=12,44 \mathrm{~m})$, indicando que foi utilizada uma segmentação ainda mais grosseira.

\subsection{Análise de Sensibilidade da Discretização}

Será utilizado o exemplo da Figura C6 do IEEE-80 /1986, malha em solo uniforme com espaçamento variável para uma análise de sensibilidade aos parâmetros da discretização.

Serão analisadas as variações do valor da resistência de aterramento, do valor máximo do potencial na superfície e do valor do potencial de toque máximo.

A discretização dos cabos será feita em 1, 9, 17 e 33 subdivisões, correspondentes a nenhuma subdivisão, 1, 2 e 4 subdivisões por mesh respectivamente.

A discretização das hastes será feita em 1, 3, 5 e 11 subdivisões.

A Figura 18 mostra a variação da resistência de aterramento.
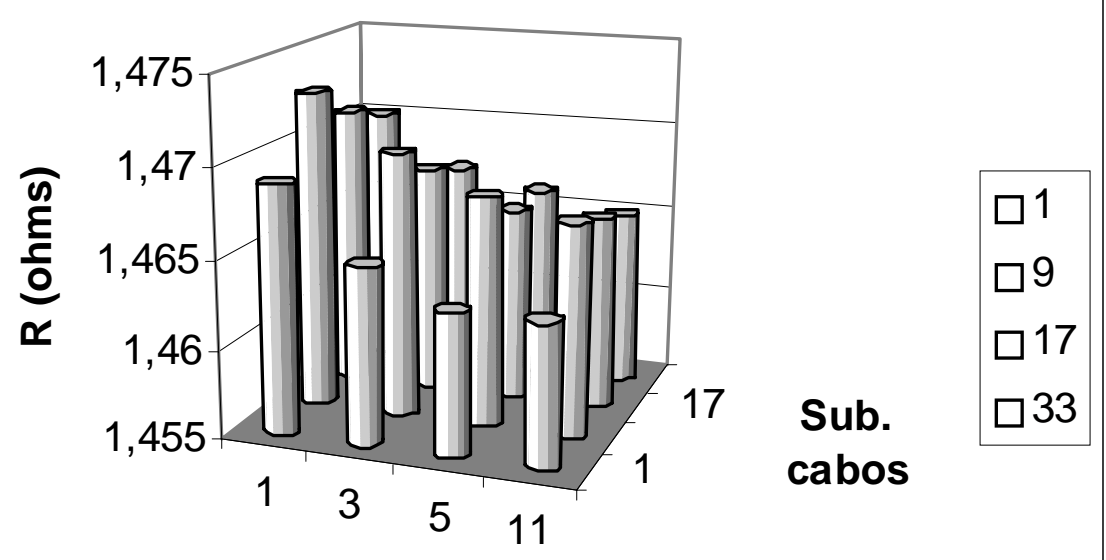

Sub. hastes

Figura 18 - Variação do valor da resistência de aterramento 
A variação entre o menor valor e o maior foi de $0,7 \%$, indicando que o valor da resistência depende pouco da discretização.

A Figura 19 mostra a variação do valor do potencial de toque máximo.

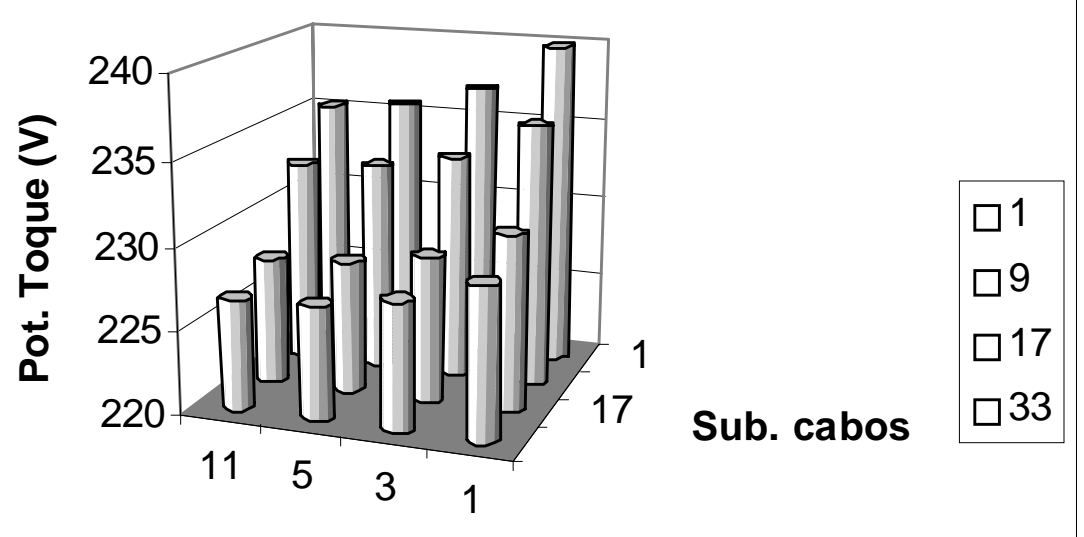

Sub. hastes

Figura 19 - Potencial de toque máximo

A variação entre o menor e o maior valor foi de $5,8 \%$, com os valores menores acontecendo com um número maior de subdivisões.

Para que o valor fique dentro de $1 \%$ do valor assintótico a subdivisão dos cabos deve ser de 17 ou 2 subdivisões por mesh e a subdivisão de hastes deve ser 3, minimizando o número total de segmentos discretos.

Observar que neste caso a conclusão de Garret em [22] de que a subdivisão das hastes tem um impacto maior sobre os potenciais na superfície não é aplicável, mostrando que malhas de forma complexa devem ser analisadas caso a caso. 
A Figura 20 mostra a variação do valor do potencial máximo na superfície.

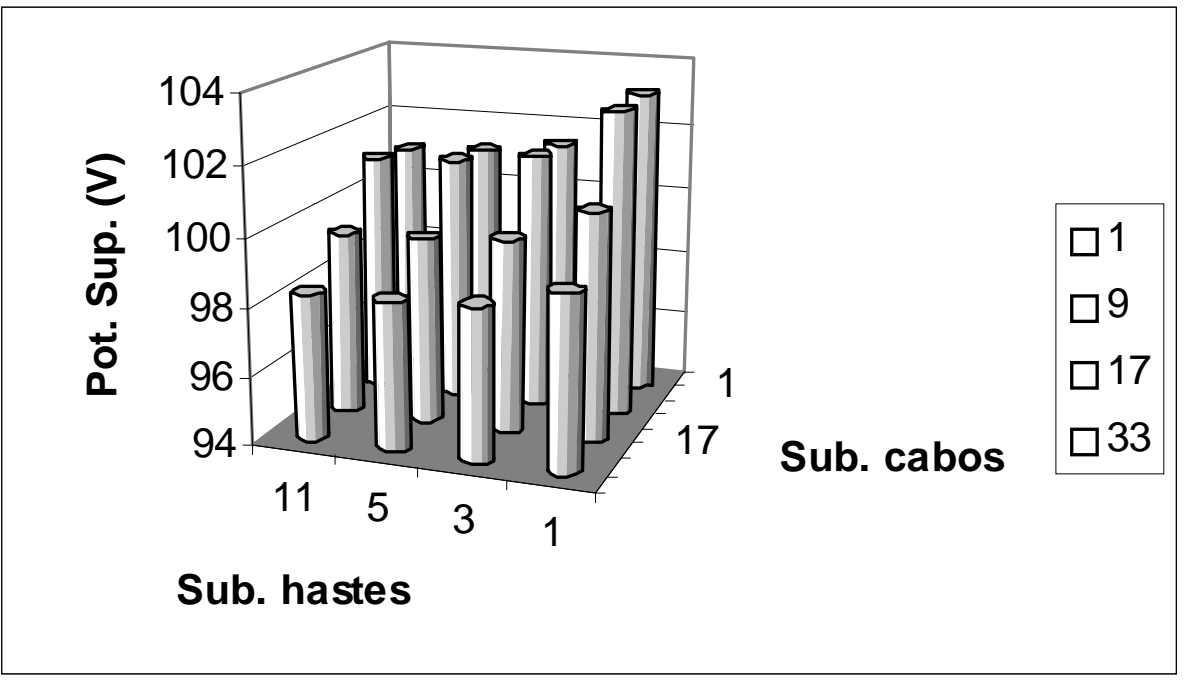

Figura 20 - Potencial máximo na superfície

A variação entre o maior e o menor valor foi de $4,9 \%$ com valores menores acontecendo com um número maior de subdivisões. Os valores maiores que $100 \%$ são incorretos, pois a superfície não pode estar a um potencial maior do que o da própria malha.

Para que a diferença fique dentro de $1 \%$ do valor assintótico devemos ter a mesma condição necessária para o potencial de toque, subdivisão dos cabos de 2 por mesh e 03 subdivisões para as hastes.

Esta correlação tem significado físico, pois como há pequena variabilidade no valor da resistência de aterramento e uma discretização mais grosseira aumenta os valores máximos e mínimos do potencial na superfície, se a discretização reproduz 
adequadamente o valor máximo do potencial na superfície ela também reproduzirá adequadamente o valor mínimo, associado ao potencial de toque.

Uma consequiência imediata desta correlação é que o potencial na superfície pode ser usado como um indicador da qualidade da discretização.

É interessante verificar o efeito da discretização no valor do potencial sobre a superfície dos eletrodos, pois uma das hipóteses fundamentais é que o potencial sobre a superfície dos eletrodos é constante.

A Figura 21 mostra o potencial sobre a superfície do cabo central da malha em percentagem do valor médio para nenhuma subdivisão de cabos e hastes e para 2 subdivisões por mesh para os cabos e 3 subdivisões para as hastes, segmentação que produziu valores dentro de $1 \%$ dos valores assíntotas.

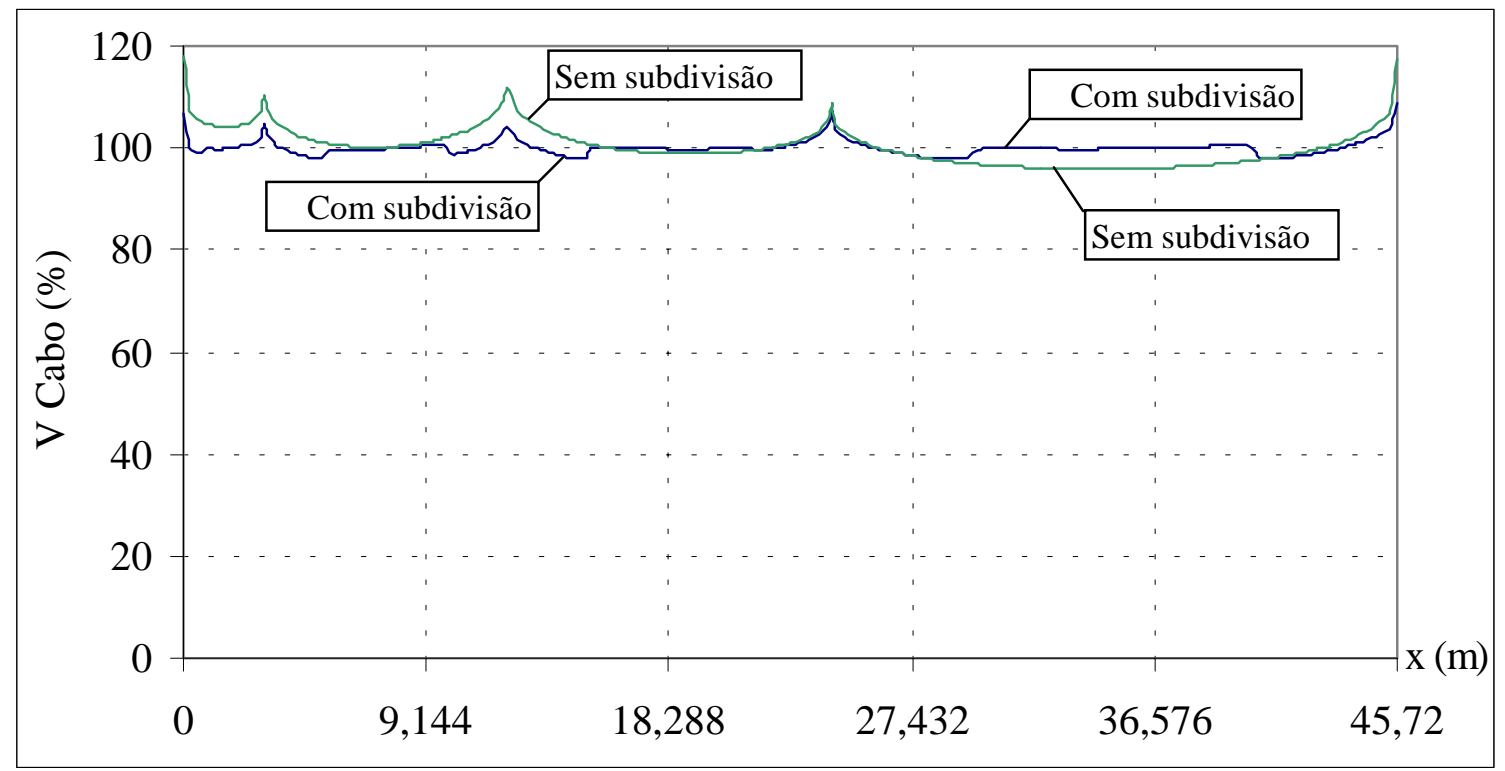

Figura 21 - Potencial sobre a superfície do cabo central 
Pode-se observar que a subdivisão mais fina proporcionou uma melhor aderência à hipótese, com o potencial da superfície do cabo se aproximando mais do valor médio.

A forma dos potenciais na Figura 21 indica que a ocorrência de potenciais na superfície do solo com valores superiores ao valor médio do potencial da malha decorre justamente da falta de aderência à hipótese básica de potencial constante em todo o eletrodo. 


\section{CONCLUSÃO}

Os resultados apresentados permitem concluir que a técnica de imagens complexas pode ser utilizada com sucesso para o cálculo de malhas de terra em solos com múltiplas camadas horizontais.

A análise teórica realizada permitiu uma explicitação inédita das funções kernel para posições arbitrárias da fonte e do objeto, possibilitando que outros trabalhos futuros possam ser realizados com base nas funções kernel.

O programa AMAICom desenvolvido superou as limitações existentes em trabalhos anteriores de imagens complexas, permitindo o cálculo de malhas com eletrodos situados em qualquer camada e a determinação das imagens complexas por um método mais robusto e estável.

Ainda existem pontos importantes a serem aprofundados tais como:

- redução do número de amostras da função kernel;

- propagação do erro proveniente do uso das imagens complexas para o cálculo dos potenciais e, consequentemente, para o cálculo das resistências mútuas e

- efeitos da discretização dos eletrodos em malhas com topologia irregular. 


\section{REFERÊNCIAS BIBLIOGRÁFICAS}

[ 1] Cardoso, J. R. O Método dos Elementos Finitos Aplicado na Determinação da Resistência de Aterramento. Anais do Seminário sobre Cálculo de Campo Elétrico com Métodos Numéricos, Santo André, 1985.

[ 2] Cardoso, J. R. ; Ribeiro, F. S. ; Gambirasio, G. O Método dos Elementos Finitos no Modelamento de Sistemas de Aterramento em Solos de Múltiplas Camadas. Anais do IX SNPTEE, Belo Horizonte, 1987.

[ 3] Cardoso, J. R. ; Oliveira, J. B. Ground-3D: Um Sistema CAD / CAE para Análise de Sistemas de Aterramento. Anais do XI SNPTEE, Rio de Janeiro, 1991.

[ 4] Leite, C. M. ; Pereira $F^{o}$, M. L. Técnicas de Aterramentos Elétricos. São Paulo, Officina de Mydia, 1995.

[ 5] Dwight, H. B. Calculation of Resistances to Ground. AIEE Transaction, Vol 55, Dec 1936, pg 1318-1328.

[ 6] Gross, E. T. B.; Chitnis, B. V.; Stratton, L. J. Grounding Grids for High-Voltage Stations. AIEE Trans. Vol 72, pt. III (Power Apparatus and Systems), Aug 1953,pg 799-810.

[ 7] Thapar, B. ; Gross, E. T. B. Grounding Grids for High Voltage Stations IV Resistance of Grounding Grids in Nonuniform Soil. AIEE Transactions, Oct 1963,pg $782-788$.

[ 8] Tagg, G. F. Earth Resistances. London, George Newnes, 1964. 
[ 9] Sunde, E. D. Earth Conduction Effects in Transmission Systems. New York, Dover, 1968.

[ 10] Giao, T. N. ; Sarma, M. P. Effect of a Two-Layer Earth on the Electric Field near HVDC Ground Electrodes. IEEE Trans. on PAS, 1972, № 6, Nov/Dec, pg 2356 - 2365.

[ 11] Dawalibi, F. ; Mukhedkar, D. Optimum Design of Substation Grounding in a Two Layer Earth Structure Part I - Analytical Study. IEEE Trans on PAS, Vol 94, № 2 , mar/apr 1975, pg 252-261.

[ 12] Dawalibi, F. ; Mukhedkar, D. Optimum Design of Substation Grounding in a Two Layer Earth Structure Part II - Comparison between Theorethical and Experimental Results. IEEE Trans on PAS, Vol 94, N² 2, mar/apr 1975, pg 262-266.

[ 13] Dawalibi, F. ; Mukhedkar, D. Optimum Design of Substation Grounding in a Two Layer Earth Structure Part III - Study of Grounding Grids Perfomance and New Electrodes Configuration. IEEE Trans on PAS, Vol 94, № 2, mar/apr 1975, pg 267-272.

[14] Dawalibi, F. ; Mukhedkar, D. Multi Step Analysis of Interconnected Grounding Electrodes. IEEE Trans on PAS, Vol 95, N 1, Jan/Feb 1976, pg 113-119.

[ 15] Dawalibi, F. ; Mukhedkar, D. Resistance Calculation of Interconnected Grounding Electrodes. IEEE Trans on PAS, Vol 96, N 1, Jan/Feb 1977, pg 59-65.

[ 16] Dawalibi, F. ; Mukhedkar, D. Transferred Earth Potentials in Power Systems. IEEE Trans on PAS, Vol 97, N 1, Jan/Feb 1978, pg 90-101.

[ 17] Dawalibi, F. ; Mukhedkar, D. Influence of Grounds Rods on Grounding Grids. IEEE Trans on PAS, Vol 98, N 6, Nov/Dec 1979, pg 2089-2098. 
[ 18] Heppe, R. J. Computation of Potential at Surface above na Energized Grid or other Electrode, allowing for Non-Uniform Current Distribution. IEEE Trans on PAS, Vol 98, № 6, Nov/Dec 1979, pg 1978-1989.

[ 19] Kouteynikoff, P. Numerical Computations of the Grounding Resistance of Substations and Towers. . IEEE Trans on PAS, Vol 99, N³, May/Jun 1980, pg 957965.

[ 20] Nagar, R. P. ; Velazquez, R. ; Loeloeian, M. ; Mukhedkar, D. ; Gervais, Y. Review of Analytical Methods for Calculating the Perfomance of Large Grounding Grid Electrodes Part I : Theorethical Considerations. IEEE Trans on PAS, Vol 104, N 11, Nov 1985, pg 3124-3133.

[ 21] Loeloeian, M. ; Velazquez, R. ; Mukhedkar, D. Review of Analytical Methods for Calculating the Perfomance of Large Grounding Grid Electrodes Part II : Numerical Results. IEEE Trans on PAS, Vol 104, № 11, Nov 1985, pg 3133-3139.

[ 22] Garret, D. L. ; Pruitt, J. G. Problems Encountered with the Average Potential Method of Analyzing Substation Grounding Systems. IEEE Trans on PAS, Vol 104, N 12, Dec 1985, pg 3586-3596.

[ 23] ANSI / IEEE Std 80-1986, IEEE Guide for Safety in AC Substation Grounding. New York, IEEE Press, 1986.

[ 24] Joy, E. B. ; Wilson, R. E. Accuracy Study of the Ground Grid Analysis Algorithm. IEEE Trans on PWRD, Vol 1, N³, Jul 1986, pg 97-103. 
[ 25] Kovarsky, D. ; Pinto, L. J. ; Caroli, C. E. ; Santos, N. Soil Surface Potentials Induced by Itaipu HVDC Ground Return Current. IEEE Trans on PWRD, Vol 3, $\mathrm{N}^{\circ} 3$, Jul 1988, pg 1204-1210.

[ 26] Lagace, P. J. ; Houle, J. L. ; Gervais, Y. ; Munkhedkar, D. Evaluation of the Voltage Distribution around Toroidal HVDC Ground Electrodes in N-Layer Soils. IEEE Trans on PWRD, Vol 3, N 4, Oct 1988, pg 1573-1579.

[ 27] Takahashi, T. ; Kawase, T. Calculation of Earth resistance for a Deep-Driven Rod in a Multi-Layer Earth Structure. IEEE Trans on PWRD, Vol 6, N², Apr 1991,pg 608-614.

[28] Dawalibi, F. ; Barbeito, N. Measurements and Computations of the Performance of Grounding Systems Buried in Multilayer Soils. IEEE Trans on PWRD, Vol 6, N 4, Oct 1991, pg 1483-1490.

[ 29] Chow, Y. L. ; Srivastava, K. D. Complex Images of a Ground Electrode en Layered Soils. J. of Applied Physics, Vol 71, N 15, Jan 1992, pg 569-574

[ 30] Dawalibi, F. ; Ma, J. ; Southey, R. D. Behaviour of Grounding Systems in Multilayer Soils : A Parametric Analysis. IEEE Trans on PWRD, Vol 9, № 1, Jan 1994 , pg 334-342.

[ 31] Chow, Y. L. ; Yang, J. J. ; Srivastava, K. D. Grounding Resistance of Buried Electrodes in Multi-Layer Earth Predicted by Simple Voltage Measurements along Earth Surface - A Theoretical Discussion. IEEE Trans on PWRD, Vol 10, $\mathrm{N}^{\circ}$ 2, Apr 1995, pg 707-713. 
[ 32] Elsherbiny, M. M. ; Chow, Y. L. ; Salama, M. M. A Fast and Accurate Analysis of Grounding Resistance of a Driven Rodbed in a Two-Layer Soil. Paper presented at the IEEE/PES Summer Meeting, July 23-27, 1995, Portland - USA.

[ 33] Li, Z. ; Yuan, J. ; Zhang, L. Lu, J. The Simulated Calculation of Power Station Grounding Systems with Grid and Driven Rods Based on an Equivalent Image Method. Paper presented at the $11^{\text {a }}$ COMPUMAG, November, 03-06, 1997, Rio de Janeiro Brasil.

[ 34] Vujevic, S.; Kurtovic, M. Numerical Analysis of Earthing Grids Buried in Horizontally Stratified Multilayer Earth. Int. Journal for Numerical Methods in Engineering, Vol 41, 1998,pg 1297 - 1319.

[ 35] Sadiku, M, Numerical Techniques in Electromagnetics. Boca Raton, CRC Press, 1992.

[ 36] Haffner, S. L.; Telló, M. ; Dias, G. A. D. Método Computacional para Projeto de Grandes Sistemas de Aterramento Empregando Matrizes Esparsas. Artigo apresentado no XIV Congresso Íbero Latino-Americano de Métodos Computacionais em Engenharia , 1 a 3 de dezembro de 1993, São Paulo - Brasil.

[ 37] Chew, W. C. Waves and Fields in Unhomogeneous Media. New York, IEEE Press, 1995.

[ 38] Press at all, Numerical Recipes in Pascal. London, Cambridge Press, 1989.

[ 39] Blaricum, M.; Mittra, R. Problems and Solutions Associated with Prony's Method for Processing Transient Data. IEEE Trans on Antennas and Propagation, Vol AP-26, $\mathrm{N}^{\circ}$ 1, Jan 1978, pg 174-182. 